\title{
Credit Default Swaps and the Empty Creditor Problem
}

\author{
Patrick Bolton \\ Columbia University \\ Martin Oehmke \\ Columbia University
}

\begin{abstract}
The empty creditor problem arises when a debtholder has obtained insurance against default but otherwise retains control rights in and outside bankruptcy. We analyze this problem from an ex ante and ex post perspective in a formal model of debt with limited commitment, by comparing contracting outcomes with and without insurance through credit default swaps (CDS). We show that CDS, and the empty creditors they give rise to, have important ex ante commitment benefits: By strengthening creditors' bargaining power, they raise the debtor's pledgeable income and help reduce the incidence of strategic default. However, we also show that lenders will over-insure in equilibrium, giving rise to an inefficiently high incidence of costly bankruptcy. We discuss a number of remedies that have been proposed to overcome the inefficiency resulting from excess insurance. (JEL G30, G32, G33)
\end{abstract}

One of the most significant changes in the debtor-creditor relationship in the past few years has been the creation and subsequent exponential growth of the market for credit insurance, in particular credit default swaps (CDS). An important aspect of this development is that credit insurance with CDS does not just involve a risk transfer to the insurance seller. It also significantly alters the debtor-creditor relation in the event of financial distress, as it partially or fully separates the creditor's control rights from his cash-flow rights. Legal scholars (Hu and Black 2008a,b) and financial analysts (e.g., Yavorsky 2009) have raised concerns about the possible consequences of such a separation, arguing that CDS may create empty creditors-holders of debt and CDSwho no longer have an interest in the efficient continuation of the debtor, and who may push the debtor into inefficient bankruptcy or liquidation.

\footnotetext{
We are especially grateful to an anonymous referee for many helpful comments. We also thank Ron Anderson, Bernard Black, Craig Brown, Charles Calomiris, Pierre Collin-Dufresne, Florian Ederer, Mark Garmaise, Christopher Hennessy, Charles Jones, Samuel Lee, Richmond Mathews, Edward Morrison, and Michael Weisbach (the editor) for their comments, as well as seminar participants at Columbia University, Ohio State University, UCLA Anderson, MIT Sloan, Columbia Law School, the NBER Corporate Finance meetings, the Notre Dame conference on Market Regulation, the Second Paris Spring Corporate Finance Conference, the 2010 EFA meetings in Frankfurt, the University of Michigan, and the 2011 AFA meetings in Denver. Send correspondence to Patrick Bolton, Columbia Business School, 804 Uris Hall, 3022 Broadway, New York, NY 10027; telephone: (212) 854-9245. E-mail: pb2208@ columbia.edu. Martin Oehmke, Columbia Business School, 420 Uris Hall, 3022 Broadway, New York, NY 10027; telephone: (212) 851-1804. E-mail: moehmke@ columbia.edu.
}

(C) The Author 2011. Published by Oxford University Press on behalf of The Society for Financial Studies. All rights reserved. For Permissions, please e-mail: journals.permissions@oup.com. doi:10.1093/rfs/hhr002 
In this article, we formally analyze the effects of CDS in a limitedcommitment model of credit to determine both the ex ante and ex post consequences of default insurance on debt outcomes. We argue that, while a creditor with a CDS contract may indeed be more reluctant to restructure the debt of a distressed debtor, it does not necessarily follow that the presence of CDS will inevitably lead to an inefficient outcome. When the debtor has limited ability to commit to repay his debt, a CDS strengthens the creditor's hand in ex post debt renegotiation and thus may actually help increase the borrower's debt capacity. The relevant question is thus whether the presence of CDS leads to debt market outcomes in which creditors are excessively tough even after factoring in these ex ante commitment benefits of CDS. Our model allows us to characterize the socially efficient level of CDS protection that trades off the costs and benefits of CDS, and the privately optimal level of credit protection, which may differ from the social optimum, in the sense that creditors may seek excessively large CDS positions. In addition, our model predicts that this over-insurance problem worsens when debt is owned by multiple creditors. Finally, our analysis sheds new light on potential policy interventions to mitigate or eliminate the empty creditor problem.

In a CDS, the protection seller agrees to make a payment to the protection buyer in a credit (default) event on a prespecified reference asset. In exchange for this promised payment, the protection seller receives a periodic premium payment from the buyer. The credit event may be the bankruptcy filing of the debtor, non-payment of the debt, and, in some CDS contracts, debt restructuring or a credit-rating downgrade. In most cases the default payment is given by the difference between the face value of the debt due and the recovery value, which is either estimated from market prices over a prespecified period after default has occurred (typically 30 days), or based on a CDS settlement auction. Settlement of the contract can be a simple cash payment, or it may involve the exchange of the defaulted bond for cash.

In our model, a firm has a positive net present value investment project, which it seeks to finance by issuing debt. However, as in Bolton and Scharfstein $(1990,1996)$ and Hart and Moore (1994, 1998), we assume that the firm faces a limited commitment problem when writing financial contracts: It cannot credibly commit to pay out cash flows in the future, since realized cash flows are not verifiable and thus their payment is not enforceable in court. As is standard in these models, non-payment can occur for two reasons: First, when interim cash flows are insufficient to cover contractual payments, a lender may be unable to pay for liquidity reasons. Second, when cash flows are sufficient to cover contractual payments but the borrower refuses to pay in full to divert cash flows to himself, non-payment occurs for strategic reasons.

The central insight of our model is that by raising the creditor's bargaining power, CDS can act as a commitment device for borrowers to pay out cash flows. That is, when creditors are insured through CDS, they stand to lose less in default and therefore are less forgiving in debt renegotiations. As 
a result, creditors are generally able to extract more in debt renegotiations, and borrowers have less of an incentive to strategically renegotiate down their debt repayments to their own advantage. However, instances may also arise in which protected creditors are unwilling to renegotiate with the debtor, even though renegotiation would be efficient. This forces the firm into Chapter 11 bankruptcy even though a debt exchange or workout would have been preferable (less costly).

There is growing anecdotal evidence for this CDS-induced shift in bargaining powerfrom debtors tocreditors. ${ }^{1}$ In 2001-2002, notlong after the creation of CDS markets, Marconi, the British telecom manufacturer, was unable to renegotiate with a syndicate of banks, some of which had purchased CDS protection. Marconi was eventually forced into a debt-for-equity swap that essentially wiped out equity holders. In 2003, Mirant Corporation, an energy company based in Atlanta, sought Chapter 11 bankruptcy protection when it was unable to work out a deal with its creditors, many of which had bought credit protection. Remarkably, the bankruptcy judge in this case took the unusual step of appointing a committee to represent the interests of equity holders in Chapter 11 (typically, once a company enters Chapter 11, equity holders lose all claims on the firm). In the judge's opinion, there was a reasonable chance that the reorganization value would be high enough to allow equity holders to obtain a positive claim after making all creditors whole, suggesting that the reason for the filing was an empty creditor problem, and not an economic insolvency.

More recently, the issue of empty creditors resurfaced in the 2009 bankruptcy negotiations of the U.S. auto companies General Motors and Chrysler, the amusement park operator Six Flags, the Dutch petrochemicals producer Lyondell Basell, the property investor General Growth Properties, and the Canadian paper manufacturer Abitibi Bowater, all of which filed for Chapter 11 protection when they were unable to work out deals with their creditors. Harrah's Entertainment, the casino operator, only barely managed to restructure its debt, and, after two failed exchange offers, the IT provider Unisys had to give its creditors a particularly sweet deal (bonds worth more than par) to reschedule debt coming due in 2010. Most recently, the trucking company YRC only managed to restructure its debt at the last minute, when the Teamsters union threatened to protest in front of the offices of hold-out hedge funds, which were allegedly blocking YRC's debt-for-equity exchange offer so as to trigger a default and cash in on more lucrative CDS payments.

We begin by highlighting the potential ex ante benefits of CDS protection as a commitment device in renegotiations: A key consequence of the stronger bargaining power of creditors with CDS is that firms can increase their debt capacity. This means that in the presence of CDS, more positive net present value projects can receive financing ex ante. Also, projects that can be financed

1 Table 1 provides a summary of instances in which empty creditors may have played a role during restructuring. The table also provides references to the relevant news media sources for each case. 


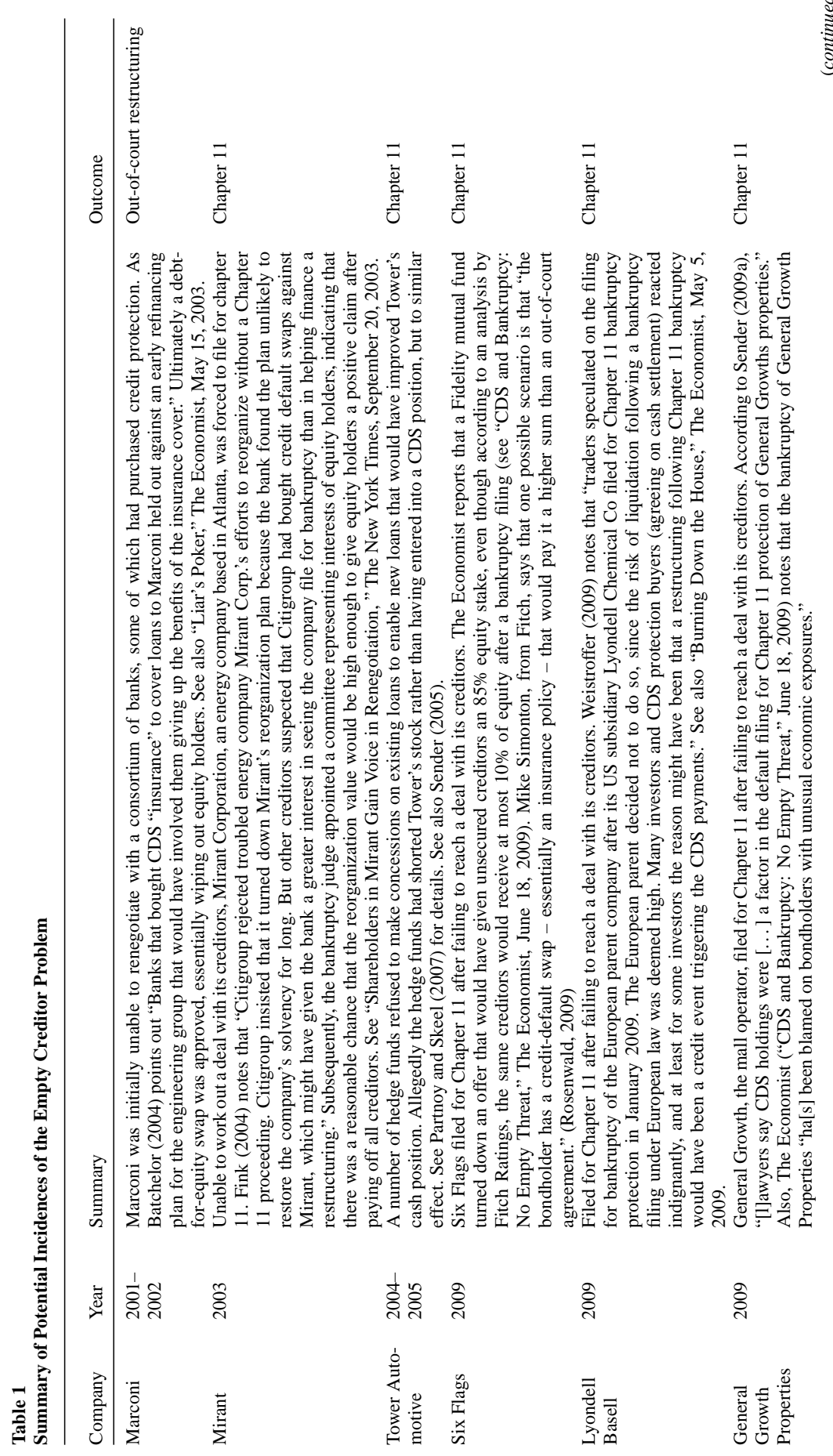




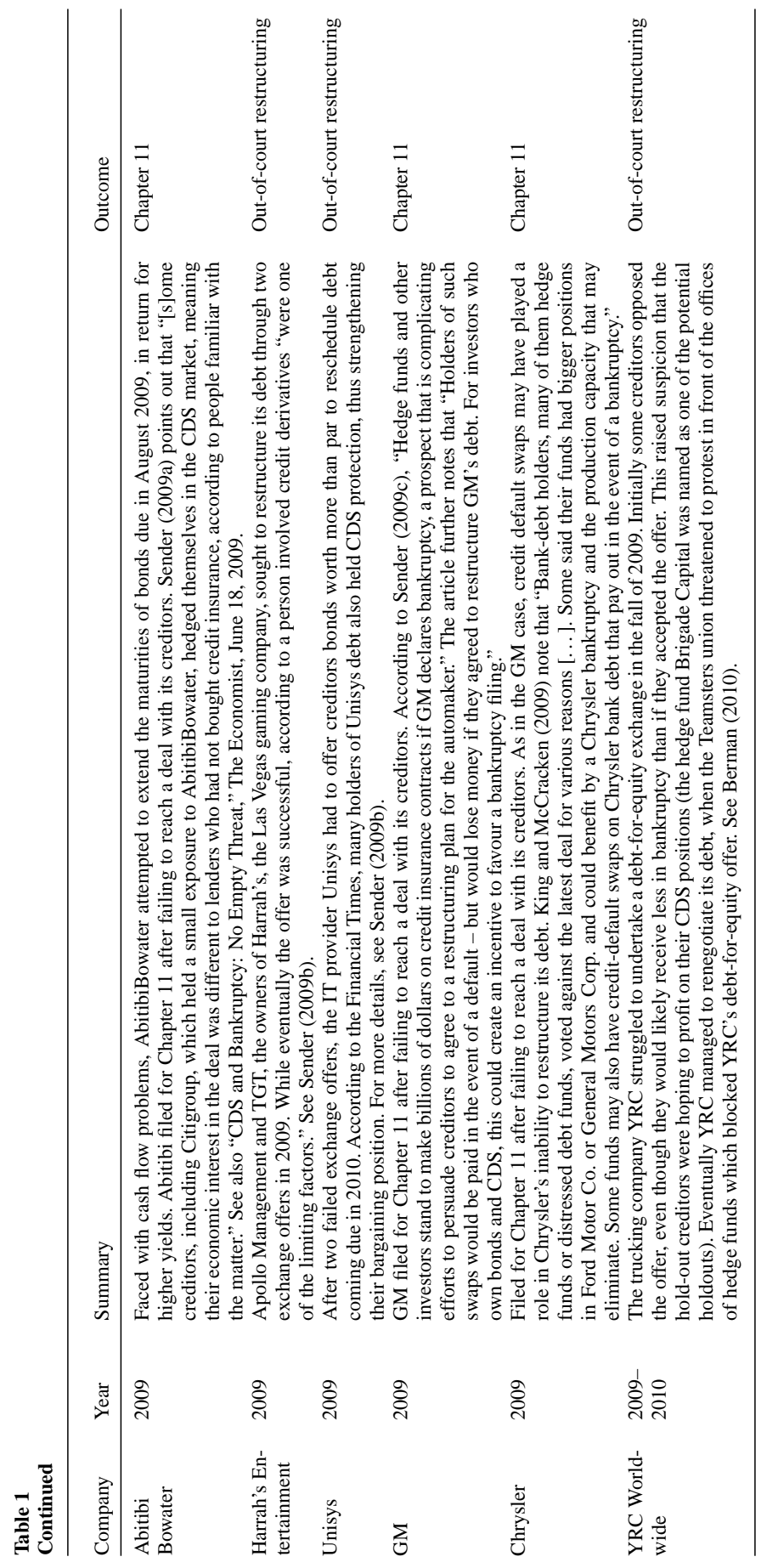


in the absence of CDS may get more efficient financing, as the presence of CDS lowers the borrower's incentive to inefficiently renegotiate down payments for strategic reasons. Taken together, this implies that under limited commitment CDS can have significant ex ante benefits.

This insight leads to a more general point about the economic role of CDS markets. In the absence of any contractual incompleteness, introducing a CDS market would not lead to gains from trade in our model, given that both parties involved are risk neutral. More generally, in any complete market structure, CDS contracts are redundant securities. This raises the question of why CDS markets exist in the first place. Our model highlights that, besides reducing the transaction costs of insurance or risk transfer, CDS introduce gains from contracting by allowing the lender to commit not to renegotiate debt unless the renegotiation terms are attractive enough for creditors.

Despite this beneficial role as a commitment device, CDS can still lead to inefficiencies. The reason is that when lenders freely choose their level of credit protection, they will generally over-insure: While the socially optimal choice of credit protection trades off the ex-ante commitment benefits that arise from creditors' increased bargaining power against the ex-post costs of inefficient renegotiation, creditors do not fully internalize the cost of foregone renegotiation surplus that arises in the presence of credit insurance. Even when insurance is fairly priced and correctly anticipates the creditors' potential valuedestroying behavior in renegotiation, creditors have an incentive to over-insure. This gives rise to inefficient empty creditors who refuse to renegotiate with lenders in order to collect payment on their CDS positions, even when renegotiation via an out-of-court restructuring would be the socially efficient alternative. This over-insurance is inefficient ex post but also-and more importantly - ex ante. In equilibrium, the presence of a CDS market will thus produce excessively tough creditors and an incidence of bankruptcy that is inefficiently high compared to the social optimum.

The legal scholarship (Hu and Black 2008a,b; Lubben 2007) has mostly focused on the detrimental ex post consequences of empty creditors for efficient debt restructuring. Hence, the resulting policy proposals regarding the treatment of CDS in and outside bankruptcy risk underestimating some of the potential ex ante benefits of CDS markets. In particular, a rule that has the effect of eliminating the empty creditor problem altogether, for example by stripping protected creditors of their voting rights or by requiring the inclusion of restructuring as a credit event in all CDS contracts, would not be efficient according to our analysis. While such a rule would prevent CDS protection from inhibiting efficiency-enhancing debt restructuring, it would also eliminate any positive commitment effects of CDS for borrowers. A similar effect would obtain if CDS were structured like put options, whereby the protection buyer can sell the bond at any time to the protection seller for a prespecified price. However, our analysis does suggest that disclosure of CDS positions may mitigate the inefficiencies resulting from the empty creditor problem, without 
undermining the ex ante commitment effect of CDS. In particular, if public disclosure allows borrowers and lenders to contract on CDS positions, they may allow the lender to commit not to over-insure once he has acquired the bond. More generally, public disclosure of positions may also be beneficial by giving investors a more complete picture of creditors' incentives in restructuring.

Our article is part of a growing theoretical literature on CDS and their effect on the debtor-creditor relationship. We add to the existing literature by emphasizing the effects of CDS on renegotiation between debtors and creditors, and the associated costs and benefits. Much of the existing literature has focused either on the impact of CDS on banks' incentives to monitor, or on the ability of CDS to improve risk sharing. In Duffee and Zhou (2001), CDS allow for the decomposition of credit risk into components that are more or less information sensitive, thus potentially helping banks overcome a lemon's problem when hedging credit risk. Thompson (2007) and Parlour and Winton (2008) analyze banks' decisions to lay off credit risk via loan sales or by purchasing CDS protection and characterize the efficiency of the resulting equilibria. Arping (2004) argues that CDS can help overcome a moral hazard problem between banks and borrowers, provided that CDS contracts expire before maturity. Parlour and Plantin (2008) analyze under which conditions liquid markets for credit risk transfer can emerge when there is asymmetric information about credit quality. Morrison (2005) argues that since CDS can undermine bank monitoring, borrowers may inefficiently switch to bond finance, thus reducing welfare. Allen and Carletti (2006) show that credit risk transfer can lead to contagion and contribute to financial crises. Stulz (2010) discusses the role of CDS during the credit crisis of 2007-2009.

Another, related literature deals with the decoupling of voting and cash-flow rights in common equity through the judicious use of derivatives to hedge cashflow risk. Hu and Black (2006, 2007) and Kahan and Rock (2007) argue that such decoupling can give rise to the opposite voting preferences from those of unhedged common equity holders and thus to inefficient outcomes, such as voting for a merger which results in a decline in the stock price of the acquirer, and which profits those who have built up short positions on the acquiring firm's stock. More recently, Brav and Mathews (2011) have proposed a theory of decoupling in which the hedging of cash-flow risk can facilitate trading and voting by an informed trader, but where it can also give rise to inefficient voting when hedging is cheap. In a related study, Kalay and Pant (2009) argue that rather than leading to inefficient acquisition decisions, decoupling allows shareholders to extract more surplus during takeover contests, while still selling the firm to the most efficient bidder. Zachariadis and Olaru (2010) propose a model in which a debtholder can trade in a firm's equity after a restructuring proposal has been made, but before the vote on the proposal takes place. In their model, the ability to trade generally raises the creditor's payoff, but can lead to inefficient liquidation when debt and equity markets differ in their assessment of the firm's survival probability. 
Our article generates a number of empirical predictions. First, through their commitment benefits, CDS can increase investment. This effect is in addition to the potential increases in investment through diversification benefits of CDS. The emerging empirical literature on the effects of CDS on credit market outcomes supports this prediction. Hirtle (2009) shows that greater use of CDS leads to an increase in bank credit supply and an improvement in credit terms, such as maturity and required spreads, for large loans that are likely to be issued by companies that are "named credits" in the CDS market. Ashcraft and Santos (2009) find that the introduction of CDS has led to an improvement in borrowing terms for safe and transparent firms, where banks' monitoring incentives are not likely to play a major role. Saretto and Tookes (2010) document that firms with traded CDS can sustain higher leverage and borrow at longer debt maturities. Second, our model predicts that the commitment benefits of CDS are largest for firms whose creditors' bargaining position is weak in the absence of CDS, such as firms with a low proportion of fixed assets or firms with mostly unsecured creditors. Third, firms that are likely to undergo restructuring, for example due to low credit quality or high volatility, should benefit more from the increase in creditor bargaining power brought about by CDS. On the other hand, when a CDS specifies a default payment that is disproportionately large relative to the creditor's loss in default, for a firm that was perceived to be sufficiently profitable to be able to obtain more loans ex ante, then prima facie the main purpose of such a CDS may be inefficient rent extraction.

The rest of the article is structured as follows. We outline our limited commitment model of CDS in Section 1. We then first analyze the model without CDS (Section 2) and then with CDS (Section 3). Section 4 extends the model to analyze the effect of multiple creditors. In Section 5, we discuss the model's implications for policy and optimal legal treatment of CDS. Section 6 concludes.

\section{The Model}

We consider a firm that can undertake a two-period investment project that requires an initial investment $F$ at date 0 . The project generates cash flows at dates 1 and 2. At each of those dates, cash flows can be either high or low. At date 1 , the project generates high cash flow $C_{1}^{H}$ with probability $\theta$, and low cash flow $C_{1}^{L}<C_{1}^{H}$ with probability $1-\theta$. Similarly, at date 2 , the project generates $C_{2}^{H}$ with probability $\phi$, and $C_{2}^{L}<C_{2}^{H}$ with probability $1-\phi$. The realization of $C_{2}$ is revealed to the firm at time 1 . While we will refer to $C_{2}$ literally as a cash flow, it can be interpreted more broadly as the continuation value of the firm (i.e., the present value of all future cash flows as seen from date 1). The project can be liquidated after the realization of the first-period cash flow for a liquidation value of $L<C_{2}^{L}$, which means that early liquidation of the project is inefficient. The liquidation value at date 2 is normalized to zero. 
The firm has no initial wealth and finances the project by issuing debt to a single creditor. Both the firm and the creditor are risk neutral, and the riskless interest rate is zero. The debt contract specifies a contractual repayment $R$ at date 1 . If the firm makes this contractual payment, it has the right to continue the project and collect the date 2 cash flow. If the firm fails to make the contractual date 1 payment, the creditor has the right to discontinue the project and liquidate the firm. Liquidation can be interpreted as outright liquidation, as in a Chapter 7 cash auction, or, more generally, as forcing the firm into Chapter 11 reorganization (e.g., by filing an involuntary bankruptcy petition). In the latter interpretation, $L$ denotes the expected payment the creditor receives in Chapter 11. Our assumption that $L<C_{2}^{L}$ thus implies that both liquidation and Chapter 11 are costly. ${ }^{2}$ Outright liquidation is costly because it involves early termination of the investment and a transfer of the firm's assets to second-best users. Chapter 11 is costly because of direct (e.g., fees for lawyers, accountants, etc.) and indirect (e.g., loss of customers, suppliers, or investor confidence) costs of the bankruptcy process. These costs are significant and empirically well documented. For example, Bris, Welch, and Zhu (2006) find that bankruptcy costs can reach up to $20 \%$ of a firm's assets. ${ }^{3}$

The main assumption of our model is that the firm faces a limited commitment problem when raising financing for the project, similar to Hart and Moore (1994, 1998) and Bolton and Scharfstein (1990, 1996). More specifically, we assume that only the minimum date 1 cash flow $C_{1}^{L}$ is verifiable, and that all other cash flows can be diverted by the borrower. In particular, the borrower can divert the amount $C_{1}^{H}-C_{1}^{L}$ at date 1 if the project yields the high return $C_{1}^{H}$. This means that after the date 1 cash flow is realized, the firm can always claim to have received a low cash flow, default, and pay out $C_{1}^{L}$ instead of $R$. We assume that $C_{1}^{L}<F$, such that the project cannot be financed with riskfree debt that is repaid at date 1 . In fact, there is no loss from normalizing $C_{1}^{L}$ to zero, such that for the remainder of the article we take $C_{1}^{L}=0 .{ }^{4}$

2 Our assumption that both Chapter 7 and Chapter 11 yield the same amount $L$ is not crucial. For example, Chapter 7 could yield $L_{7}$, while Chapter 11 yields $L_{11}$. In that case, $L$ can be interpreted as the maximum of the two, i.e., $L=\max \left[L_{7}, L_{11}\right]$.

3 Their paper also provides a useful summary of other empirical studies of bankruptcy costs, many of which find these costs to be significant.

4 When $C_{1}^{L}=0$, the creditor's payoff at date 1 could, in principle, also be interpreted as an equity share. However, we could allow for $C_{1}^{L}>0$, in which case the payoffs of the debt contract in our model would clearly differ from the payoffs of an equity contract. In our model, allowing for $C_{1}^{L}>0$ is isomorphic to a redefinition of the ex ante setup cost $F$ as the setup cost net of the fully pledgeable cash flow $C_{1}^{L}$. To see this, assume that the project costs $I$ dollars to set up. When $C_{1}^{L}=0$, we are in the case that we look at in the article: $F=I$. When $C_{1}^{L}>0, F$ is now equal to the setup cost minus the fully pledgeable cash flow, $F=I-C_{1}^{L}$. Using this redefinition of variables, all results carry through. Moreover, even in the case where $C_{1}^{L}=0$, there is a crucial difference between equity and the contract in our article: the creditor's right to liquidate the firm upon non-payment. Absent this control right, which is particular to a debt contract, the firm could never be induced to make any payments. 
We also assume that at date 0 none of the date 2 cash flows can be contracted upon. One justification of this assumption is that, seen from date 0 , the timing of future cash flows is too uncertain and too complicated to pin down accurately in an enforceable contract. At date 1, however, the firm and its initial creditors can make the date 2 cash flow verifiable by paying a proportional verification cost $(1-\lambda) C_{2}$, where $\lambda \in(0,1) .{ }^{5}$ The ability to verify the date 2 cash flow at date 1 opens the door for potential renegotiation between the firm and its creditor following non-payment of the date 1 claim $R .^{6}$ This has the consequence that the firm may want to strategically renegotiate down its repayment at date $1 .^{7}$

The main focus of our analysis is the effect of introducing a market for credit insurance in which lenders can purchase credit default swaps (CDS) to insure against non-payment of the contractual date 1 repayment $R$. We model the CDS market as a competitive insurance market involving risk-neutral buyers and sellers, in which CDS contracts are priced fairly. Note that in the absence of any contractual incompleteness there would be no gains from trade in this market, given that both parties are risk neutral. More generally, in any complete market, CDS contracts are redundant securities. Indeed, in practice, an implicit assumption in the pricing of these securities is that they can be costlessly replicated. This, naturally, raises the question as to why this market exists in the first place. One explanation is that the CDS allows the parties to save on transaction costs. But another explanation is the one we propose in this article, which is that CDS play another role besides insurance or risk transfer. They introduce gains from contracting arising from the commitment the lender gains not to renegotiate debt unless the renegotiation terms are attractive enough.

Formally, the CDS is a promise of a gross payment $\pi$ (or equivalently a net payment $\pi-L$ ) by the protection seller to the protection buyer (in our case the lender) if a "credit event" occurs at date 1 , against a fair premium $f$ that is paid by the protection buyer to the seller. We assume that a credit event occurs when the firm fails to repay $R$ and if upon non-payment the firm and the creditor fail to renegotiate the debt contract to mutually acceptable terms. With this type of renegotiation, we have in mind an out-of-court restructuring (e.g., through a

5 For simplicity, we assume that the date 2 cash flow cannot be made verifiable to a new creditor. In other words, existing creditors have an "informational monopoly," as is assumed, for example, in Rajan (1992). The main role of this assumption is to simplify the way we model to the distribution of the renegotiation surplus between debtor and creditors. The analysis can be extended to the situation where we drop this assumption. The main change would involve the debtor sometimes rolling over its debts with the initial creditors by borrowing from new creditors at date 1 . In this case, initial creditors only obtain $R$ when they could have obtained a higher renegotiation surplus in the event of a liquidity default.

6 This means that the verification costs can also be interpreted more broadly as direct costs of renegotiation.

7 We choose proportional verification costs because it seems reasonable that the higher the potential gains from continuation, the larger the due diligence costs incurred to audit the firm. However, none of the implications of the model depend on proportional verification costs. Strategic default is costly as long as verification costs are positive, whether they are proportional or fixed. Moreover, even when there are no verification costs, CDS will play a role by strengthening the creditor's role in renegotiation. 
debt exchange or a debt-for-equity swap). The assumption that CDS contracts do not pay out after successful renegotiation reflects what is standard practice in the CDS market. Since the spring of 2009, the default CDS contract as defined by the International Swaps and Derivatives Association (ISDA) does not recognize restructuring as a credit event. Moreover, even for CDS contracts that recognize restructuring as a credit event, in practice there is often significant uncertainty for creditors whether a particular restructuring qualifies. ${ }^{8} \mathrm{We}$ discuss the different ISDA restructuring clauses and the implications of making restructuring a credit event that triggers the CDS in Section 5.2.

If the firm misses its contractual date 1 payment $R$, two outcomes are possible: Either the lender forces the firm into bankruptcy and collects the liquidation value $L$, or the lender chooses to renegotiate the debt contract in an out-of-court restructuring. Bankruptcy is a credit event and, in exchange for the defaulted bond, triggers the payment $\pi$ by the protection seller under the CDS contract. Alternatively, if the firm and lender renegotiate the initial contract in an out-of-court restructuring, they avert costly bankruptcy (as $L<C_{2}^{L}$ ), but the lender does not receive the CDS payment $\pi$, since an out-of-court restructuring does not constitute a credit event. A workout also involves costs, because auditing the date 2 cash flows, which is a prerequisite for renegotiation, requires paying the verification $\operatorname{cost}(1-\lambda) C_{2}$. This reduces the renegotiation surplus available to the firm and creditor to $\lambda C_{2}<C_{2}$. However, workouts are less costly than bankruptcy, as we assume that $\lambda C_{2}>L$. Since for most of our analysis there is not much loss in setting $L=0$, we will make this assumption for the remainder of the article.

Finally, when renegotiation occurs, the renegotiation surplus is split between the firm and the lender according to their relative bargaining strengths. We assume that absent CDS, the relative bargaining strengths in renegotiation are exogenously given by $q$ (for the lender) and $1-q$ (for the firm). In the presence of CDS, however, the relative bargaining positions can change, since CDS protection increases the lender's outside option. In particular, if the amount the creditor receives by abandoning negotiation and triggering the CDS exceeds what he would receive as part of the bargaining game absent CDS, the firm must compensate the creditor up to his level of credit protection $\pi$ in order to be able to renegotiate. In the presence of credit protection, the creditor thus receives the maximum of what he would receive absent CDS and his outside option $\pi$ generated by the $\operatorname{CDS}: \max \left[q \lambda C_{2}, \pi\right]$. Moreover, when $\pi$ exceeds the available renegotiation surplus $\lambda C_{2}$, the CDS payment in the event of bankruptcy exceeds what the firm can offer to the creditor in renegotiation, such that renegotiation becomes impossible. Overall, CDS

\footnotetext{
8 For example, on October 5, 2009, ISDA ruled that an Alternative Dispute Resolution (ADR) that led to changes in maturity and principal of Aiful Corporation's debt did not qualify as a credit event. The ruling was subsequently overturned. See www.isda.org for more information.
} 
protection thus makes creditors tougher negotiators in out-of-court restructurings, and in the extreme case may prevent renegotiation altogether. ${ }^{9}$

Our model of debt restructuring, while highly stylized, captures the broad elements of debt restructuring in practice. Absent tax and accounting considerations, out-of-court restructuring is generally seen to be cheaper than a formal bankruptcy procedure. As for the effects of CDS protection on out-of-court restructurings, our model captures in a simple way the empty creditor effects that analysts are concerned about. As Yavorsky (2009, p. 1) argues: "While individual circumstances may vary, we believe that bondholders that own CDS protection are more likely to take a 'hard-line' in negotiations with issuers."

\section{Optimal Debt Contracts without CDS}

We begin by analyzing the model in the absence of a market for credit insurance. The optimal debt contract for this case will later serve as a benchmark to analyze the effects of introducing a CDS market.

Two types of non-payment of debt can occur in our model. If the low cash flow realizes at date 1 , the firm cannot repay $R$ as it does not have sufficient earnings to do so (since $F>C_{1}^{L}$ ). We refer to this outcome as a liquidity default. If the high cash flow realizes at date 1 , the firm is able to service its debt obligations but may choose not to do so. That is, given our incomplete contracting assumption, the firm may default strategically and renegotiate with the creditor. In particular, in the high cash-flow state the firm will make the contractual repayment $R$ only if the following incentive constraint is satisfied:

$$
C_{1}^{H}-R+C_{2} \geq C_{1}^{H}+(1-q) \lambda C_{2} .
$$

This constraint says that, when deciding whether to repay $R$, the firm compares the payoff from making the contractual payment and collecting the entire date 2 cash flow to defaulting strategically and giving a fraction $q$ of the renegotiation surplus to the creditor. The firm has an incentive to make the contractual payment whenever the date 2 cash flow is sufficiently large relative to the face value $R$, while for small expected future cash flows the firm defaults strategically.

We first establish under which conditions the project can be financed without strategic default occurring in equilibrium. Since strategic default is costly $(\lambda<$ 1), this is the optimal form of financing whenever it is feasible.From Equation

9 Formally, our bargaining protocol is equivalent to a Nash bargaining outcome in which CDS protection raises the creditor's outside option. In modeling this, we follow the Binmore-Shaked-Sutton "outside option principle," according to which a player with an outside option that exceeds what he would receive otherwise will just receive his outside option. For more details on the details of this solution and how it can be derived from non-cooperative bargaining theory, see, e.g., Sutton (1986, p. 714). While we work with the "outside option principle," our results do not depend on this particular bargaining solution. For example, we could also assume that, instead of receiving $\max \left[q \lambda C_{2}, \pi\right]$, the protected creditor receives his outside option $\pi$ plus a share $q$ of the remaining bargaining surplus, i.e., $\pi+\max \left[q\left(\lambda C_{2}-\pi\right), 0\right]$. Qualitatively, none of our results would change. See the appendix for a brief discussion. 
(1), we see that the maximum face value that satisfies the incentive constraint for both realizations of the date 2 cash is given by $R=C_{2}^{L}[1-\lambda(1-q)] .{ }^{10}$ This maximum value for $R$ in turn implies a maximum ex ante setup cost consistent with the no strategic default assumption. We summarize this in Proposition 1.

Proposition 1. Suppose that there is no strategic default. The maximum face value $R$ compatible with this assumption just satisfies the incentive constraint:

$$
C_{1}^{H}+C_{2}^{L}-R \geq C_{1}^{H}+\lambda C_{2}^{L}(1-q)
$$

yielding a maximum face value consistent with no strategic default of

$$
R=C_{2}^{L}[1-\lambda(1-q)]
$$

The maximum ex ante setup cost consistent with no strategic default is given by

$$
\widehat{F}=\theta C_{2}^{L}[1-\lambda(1-q)]+(1-\theta) \lambda q\left[\phi C_{2}^{H}+(1-\phi) C_{2}^{L}\right] .
$$

Proposition 1 states that when the ex ante setup cost of the project is not too high, the project can be financed through a debt contract such that no strategic default will occur in equilibrium, even in the absence of CDS contracts. The resulting outcome is efficient: When the firm has sufficient resources at date 1 , it chooses to repay, such that the firm only enters costly renegotiation in the liquidity default state, where it is unavoidable. Moreover, in the liquidity default state, renegotiation, while costly, is efficient and always occurs.

Inefficiencies arise when the ex ante setup cost exceeds $\widehat{F}$. As we show below, in this case the project either cannot be financed at all, or it can only be financed with strategic default occurring in equilibrium. The former is inefficient because it implies underinvestment. The latter is inefficient because renegotiation has a cost, and from an efficiency perspective should only occur when absolutely necessary (i.e., in the liquidity default state). However, when the ex ante setup costs exceed $\widehat{F}$, the face value required for the project to attract funding makes it optimal for the firm to default strategically when $C_{1}=C_{1}^{H}$ and $C_{2}=C_{2}^{L}$. Renegotiation thus occurs even in cases when it is not strictly necessary, which leads to a deadweight loss. We summarize this in Proposition 2.

10 For Proposition 1, it would be sufficient to assume that $C_{1}^{H} \geq C_{2}^{L}[1-\lambda(1-q)]$. However, we will use the slightly stronger assumption $C_{1}^{H} \geq C_{2}^{H}[1-\lambda(1-q)]$ in Proposition 2. We assume that $C_{1}^{H} \geq C_{2}^{H}[1-\lambda(1-q)]$ so that the firm can always pay the incentive compatible repayment $R$ in the high date 1 cash-flow state $C_{1}^{H}$. 
Proposition 2. When $\phi \leq \bar{\phi} \equiv \frac{(1-\lambda) C_{2}^{L}}{(1-\lambda) C_{2}^{H}+\lambda q\left(C_{2}^{H}-C_{2}^{L}\right)}$, the project cannot be financed when the setup cost exceeds $\widehat{F}$. When $\phi>\bar{\phi}$, there is an interval $\left(\widehat{F}, F^{\prime}\right]$ for which the project can be financed with strategic default arising at date 1 when $C_{2}=C_{2}^{L}$. This results in an expected inefficiency from strategic default of

$$
\theta(1-\phi)(1-\lambda) C_{2}^{L}
$$

The maximum face value of debt $R$ consistent with strategic default only in the low cash-flow state $C_{2}=C_{2}^{L}$ is given by

$$
R=C_{2}^{H}[1-\lambda(1-q)]
$$

and the maximum ex ante setup cost for which the project can be financed with strategic default only in the low cash-flow state is given by

$$
\begin{aligned}
F^{\prime}= & \theta\left[\phi C_{2}^{H}[1-\lambda(1-q)]+(1-\phi) \lambda q C_{2}^{L}\right] \\
& +(1-\theta) \lambda q\left[\phi C_{2}^{H}+(1-\phi) C_{2}^{L}\right] .
\end{aligned}
$$

Finally, when $F$ exceeds $\max \left[\widehat{F}, F^{\prime}\right]$, the project cannot be financed at all. This is because in this case there would be systematic strategic default at date 1. That is, the debt obligation $R$ is so high that in the high date 1 cash-flow state the firm defaults even when the date 2 cash-flow is $C_{2}^{H}$. This, however, implies that the pledgeable income is insufficient to finance the project.

Proposition 3. When $F>\max \left[\widehat{F}, F^{\prime}\right]$, the project cannot be financed. In this case, strategic default would always arise when $C_{1}=C_{1}^{H}$. This implies a maximum pledgeable cash flow of

$$
\bar{F}=\lambda q\left[\phi C_{2}^{H}+(1-\phi) C_{2}^{L}\right]<F^{\prime},
$$

which is insufficient to finance the project.

Propositions 1, 2, and 3 are summarized in Figure 1. Jointly, they imply that limited commitment causes two types of inefficiencies. First, while it would be efficient to fund any project for which the expected cash flows exceed the setup cost, limited commitment reduces the firm's borrowing capacity, such that only projects for which

$$
F \leq \max \left[\widehat{F}, F^{\prime}\right]<\underbrace{\theta C_{1}^{H}+(1-\theta) C_{1}^{L}+\phi C_{2}^{H}+(1-\phi) C_{2}^{L}}_{\text {expected cash flows }}
$$




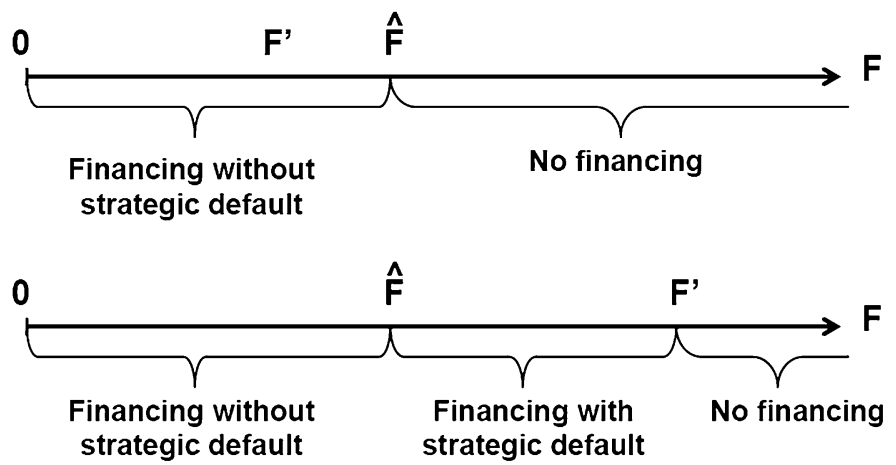

Figure 1

Financing without CDS.

The figure illustrates the two possible outcomes absent a CDS market. Either all projects up to $\widehat{F}$ receive financing without strategic default and no projects beyond $\widehat{F}$ are financed (top), or, when $\phi$ is sufficiently high, there is an additional region $\left(\widehat{F}, F^{\prime}\right]$ in which the project can be financed with strategic default occuring in equilibrium (bottom).

can be financed. Hence, limited commitment gives rise to underinvestment relative to the first-best.

Corollary 1. The equilibrium without a CDS market exhibits underinvestment relative to first-best.

Second, when $F^{\prime}$ exceeds $\widehat{F}$, there is a range of setup costs for which the project can be financed, but only inefficiently. This is because in this range strategic default occurs in equilibrium, leading to a deadweight cost since renegotiation takes place even when not strictly necessary.

Corollary 2. When $\phi>\bar{\phi}$, there is a range of ex ante setup costs $\left(\widehat{F}, F^{\prime}\right]$ for which the project can only be financed inefficiently.

These inefficiencies relative to first-best are a direct consequence of limited commitment. This highlights the potential beneficial effect of commitment devices. In particular, a direct implication of Corollaries 1 and 2 is that any mechanism that can serve as a commitment device for the firm to pledge cash flows to the creditor can be value enhancing. In Section 3, we show that CDS can serve as exactly such a commitment device.

\section{Debt, CDS, and the Empty Creditor}

We now analyze the effect of allowing the lender to purchase credit insurance in a fairly priced CDS market. As we will see, the main effect of CDS protection is to increase the lender's bargaining position in renegotiation: In order to induce the lender to accept a renegotiation offer, the firm must now 
compensate the lender for the CDS payment he could collect by forcing the firm into bankruptcy.

The increase in the lender's bargaining power has two effects. First, when creditors are protected through CDS, they are generally able to extract more surplus during renegotiation following either a liquidity default or a strategic default, thus increasing the firm's pledgeable income at date 0 . This is welfare enhancing since it allows more investment to be undertaken at time 0 .

Second, when the firm anticipates lenders to be tougher in renegotiation, this reduces the firm's incentive to strategically renegotiate down its repayment at date 1. In particular, if the borrower has a CDS position of size $\pi$, any outof-court renegotiation offer must compensate the lender for the outside option of forcing the firm into bankruptcy and collecting the insurance payment. This means that when the amount of credit insurance $\pi$ exceeds $q \lambda C_{2}$, the incentive constraint (1) becomes

$$
C_{1}^{H}-R+C_{2} \geq C_{1}^{H}+\max \left[\lambda C_{2}-\pi, 0\right] .
$$

It is easy to see that by reducing the right-hand side of this inequality, credit protection lowers the firm's incentive to default strategically. This second effect is welfare enhancing since strategic renegotiation is costly and should be avoided when possible.

However, when the lender acquires a CDS position, this can also lead to situations in which he is unwilling to renegotiate with the firm, even after a liquidity default, when renegotiation would be efficient given the positive renegotiation surplus of $\lambda C_{2}$. This happens because credit insurance can turn the lender into an inefficient empty creditor: While still owning control rights, the creditor with CDS protection is insulated from the potential value destruction that results from bankruptcy. Renegotiation then breaks down whenever the insurance payout the lender can collect in bankruptcy is larger than the potential surplus from renegotiating with the firm. This results in unrealized renegotiation gains and is clearly inefficient ex post. Moreover, when credit insurance leads to foregone renegotiation surplus for projects that could have been financed without sacrificing renegotiation surplus, it also leads to an inefficiency in an ex ante sense.

We analyze the effects of CDS insurance in two steps. As a benchmark, we first characterize the socially optimal level of credit insurance. This is the level of credit protection a social planner would set to maximize overall surplus. In our setting, it also coincides with the level of CDS protection the borrower would choose if he could determine the level of credit protection for his lenders. After establishing this benchmark, we then analyze the lender's choice of credit protection. We will show that when the lender freely chooses his CDS position, he generally has an incentive to over-insure in the CDS market, leading to a socially excessive incidence of bankruptcy and lost renegotiation surplus. In other words, our model predicts that a laissez-faire equilibrium in 
the CDS market leads to inefficiently empty creditors, even when CDS prices perfectly anticipate the creditor's inefficient behavior in renegotiation.

Before we turn to the socially and privately optimal levels of credit insurance, it is useful to establish some basic properties of the cost of credit protection $f$. Since in competitive equilibrium the CDS is actuarially fairly priced, the cost of protection $f$ equals the expected payments the protection seller has to make to the protection buyer, rationally anticipating the buyer's action regarding renegotiation or forcing bankruptcy at date 1 . This has two useful implications. First, the CDS premium $f$ is irrelevant when determining the socially optimal level of credit insurance in Section 3.1. It is a fair bet between the creditor and the protection seller and does thus not constitute a net gain or cost. Second, this property also simplifies determining the lender's privately optimal level of credit insurance in Section 3.2. In particular, when CDS are fairly priced, the value of the CDS to the lender comes entirely from strengthening his bargaining power in situations that ultimately do not trigger payment of the CDS. States in which the CDS pays out are priced into the insurance premium $f$, which means that in expected terms the creditor pays one for one for potential payouts from his CDS protection. Hence, when calculating the creditor's payoff, we only need to consider states in which default does not occur, because in expected terms the CDS payment $\pi$ and the insurance premium $f$ will exactly offset.

\subsection{Socially optimal credit insurance}

What level of credit insurance maximizes surplus? To understand the economic forces at work, we will answer this question in multiple steps. First, it is easy to see that the borrower should choose a level of credit protection of at least $\lambda C_{2}^{L}$. Setting $\pi=\lambda C_{2}^{L}$ increases the lender's bargaining position in renegotiation, while still allowing renegotiation to take place even in cases where the renegotiation surplus is low. Moreover, from the incentive constraint (10), we know that setting $\pi=\lambda C_{2}^{L}$ reduces the firm's incentive to default strategically. This raises the maximum face value consistent with no strategic default to $R=C_{2}^{L}$. In short, setting $\pi=\lambda C_{2}^{L}$ thus increases the firm's pledgeable cash flow and reduces the incentive to default strategically, without sacrificing any renegotiation surplus.

Lemma 1. It is efficient to choose a level of credit protection of at least $\pi=$ $\lambda C_{2}^{L}$. Then, the highest face value consistent with no strategic default is given by $R=C_{2}^{L}$. This translates into a maximum ex ante setup cost consistent with no strategic default of

$$
\widetilde{F}=\theta C_{2}^{L}+(1-\theta)\left(\phi \lambda \max \left[C_{2}^{L}, q C_{2}^{H}\right]+(1-\phi) \lambda C_{2}^{L}\right)>\widehat{F} .
$$

In addition, when $\phi>\widetilde{\phi} \equiv \frac{(1-\lambda) C_{2}^{L}}{C_{2}^{H}-\lambda C_{2}^{L}}$, there is an interval $\left(\widetilde{F}, \widetilde{F}^{\prime}\right]$ on which the project can be financed with strategic default in equilibrium. In this case, 

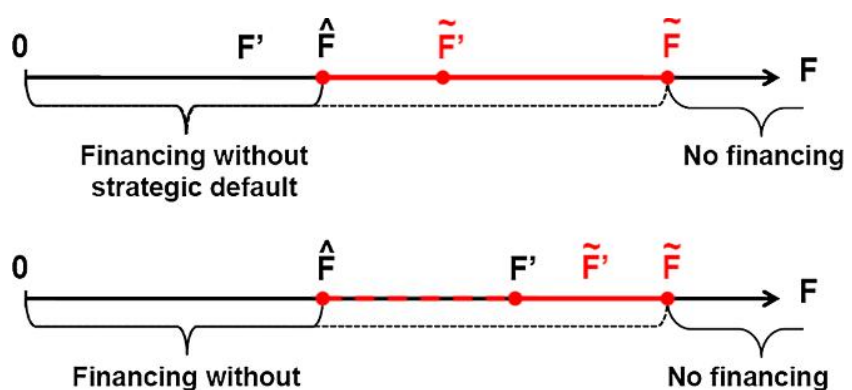

strategic default

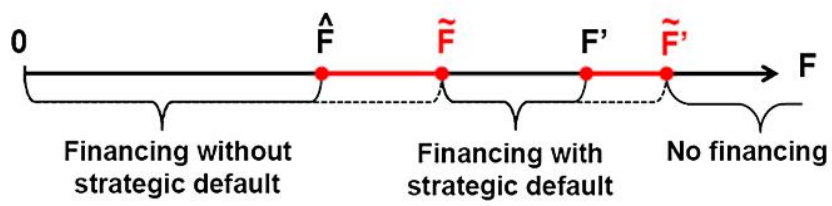

Figure 2

The two benefits of CDS.

The figure illustrates the two benefits of CDS. If absent CDS the project can be financed without strategic default for setup costs up to $\widehat{F}$ and cannot be financed beyond $\widehat{F}$, setting $\pi=\lambda C_{2}^{L}$ allows financing without strategic default up to $\widetilde{F}$ (top). When absent CDS there is a region $\left(\widehat{F}, F^{\prime}\right]$ in which financing absent CDS involves strategic default, $\pi=\lambda C_{2}^{L}$ allows financing without strategic default up to $\widetilde{F}$ (middle), or it eliminates strategic default on $(\widehat{F}, \widetilde{F}]$, and allows the financing of new projects (with strategic default) on $\left(F^{\prime}, \widetilde{F}^{\prime}\right]$ (bottom).

the maximum face value is given by $R=C_{2}^{H}$, and the project can be financed up to a maximum ex ante setup cost of

$$
\begin{aligned}
\widetilde{F}^{\prime}= & \theta\left[\phi C_{2}^{H}+(1-\phi) \lambda C_{2}^{L}\right] \\
& +(1-\theta)\left(\phi \lambda \max \left[C_{2}^{L}, q C_{2}^{H}\right]+(1-\phi) \lambda C_{2}^{L}\right)>F^{\prime} .
\end{aligned}
$$

Lemma 1 highlights two distinct benefits of CDS markets, which we illustrate in Figure 2. First, some positive NPV projects that could not attract financing in the absence of CDS can be financed when a CDS market becomes available, since $\max \left[\widetilde{F}, \widetilde{F}^{\prime}\right]>\max \left[\widehat{F}, F^{\prime}\right]$. This means that the introduction of CDS alleviates the underinvestment inefficiency. Second, when $\widehat{F}<F^{\prime}$, the presence of CDS protection can reduce the incidence of strategic default. Projects for which the setup cost $F$ lies in the interval $\left(\widehat{F}, F^{\prime}\right]$ can attract financing even in the absence of CDS, but only with strategic default in equilibrium. For these projects, the introduction of CDS eliminates strategic default and the associated deadweight loss of $\theta(1-\phi)(1-\lambda) C_{2}^{L}$. A CDS market can thus make existing projects more efficient and allow for financing of additional projects, alleviating both inefficiencies outlined in Corollaries 1 and 2. As shown in Lemma 1, if the ex ante setup cost lies below the threshold 
$\max \left[\widetilde{F}, \widetilde{F}^{\prime}\right]$, both these efficiency gains are possible without sacrificing any renegotiation surplus.

Corollary 3. CDS have two distinct benefits:

1. CDS increase the set of projects that can receive financing.

2. The presence of CDS eliminates strategic default for some projects that can be financed even in the absence of CDS.

Could it be efficient to raise the level of CDS protection beyond $\lambda C_{2}^{L}$ ? In this case, an additional effect emerges: The presence of CDS protection may prevent socially desirable renegotiation following a default. More precisely, when the firm seeks to renegotiate its debt after a low cash-flow realization at date 1 , renegotiation cannot occur when the expected date 2 cash-flow turns out to be $C_{2}^{L}$, even though renegotiation would be socially efficient. The reason is that in this case the maximum the firm can offer to the lender in renegotiation is $\lambda C_{2}^{L}$, such that the lender prefers to collect his insurance payment of $\pi>\lambda C_{2}^{L}$. Hence, setting $\pi>\lambda C_{2}^{L}$ leads to inefficient renegotiation.

However, despite this loss of renegotiation surplus, it may still be efficient to set the level of CDS protection to $\lambda C_{2}^{H} \cdot{ }^{11}$ This is the case when this higher level of credit protection allows a project to be financed that could otherwise not be financed, or if the loss of renegotiation surplus generated by the high level of credit protection is more than offset by a reduction in the social cost of strategic default. We will now consider these two cases in turn.

First, consider the case when $\widetilde{F} \geq \widetilde{F}^{\prime}$. In this case, the last project that can be financed with the low level of credit protection $\pi=\lambda C_{2}^{L}$ is financed efficiently (i.e., without strategic default). Raising the level of credit insurance to $\lambda C_{2}^{H}$ can then only be efficient for projects for which the setup cost exceeds the critical value $\widetilde{F}$, such that the project could not be financed at all when $\pi=\lambda C_{2}^{L}$. Hence, if setting $\pi=\lambda C_{2}^{H}$ makes sufficient cash flow pledgeable so that a project with a setup cost higher than $\widetilde{F}$ can be financed, it is ex ante efficient to do so, even though renegotiation will be impossible in some states of the world.

Lemma 2. Suppose that $\widetilde{F} \geq \widetilde{F}^{\prime}$. When the project's ex ante setup cost exceeds $\widetilde{F}$, it is efficient to set the level of credit protection to $\pi=\lambda C_{2}^{H}$ if this allows the project to be financed. There is a non-empty set of such projects,

11 When the level of credit protection exceeds $\lambda C_{2}^{L}$, it is always optimal to raise it up to $\lambda C_{2}^{H}$ to maximize the effect of increased bargaining power. Any level beyond $\lambda C_{2}^{H}$ will eliminate renegotiation altogether and is strictly dominated. 
with setup costs in $\left(\widetilde{F}, F^{\#}\right]$ whenever $C_{2}^{H}$ exceeds $\bar{C}_{2}$, where

$$
\bar{C}_{2}= \begin{cases}\frac{1-\phi}{(1-q) \phi} C_{2}^{L} & \text { when } q C_{2}^{H}>C_{2}^{L} \\ \frac{1}{\phi} C_{2}^{L} & \text { otherwise. }\end{cases}
$$

While this results in expected lost renegotiation surplus of $(1-\theta)(1-\phi) \lambda C_{2}^{L}$, it is ex ante efficient when $F>\widetilde{F}$, since otherwise the project could not be financed. The maximum ex ante setup cost that can be financed in this case is given by

$$
F^{\#}=\theta \max \left[C_{2}^{L}, \phi C_{2}^{H}\right]+(1-\theta) \phi \lambda C_{2}^{H}
$$

Now consider what happens when $\widetilde{F}^{\prime}>\widetilde{F}$. In this case, the marginal project that can be financed with $\pi=\lambda C_{2}^{L}$ involves strategic default. Again, it is clearly always efficient to set $\pi=\lambda C_{2}^{H}$ when this allows a project with a setup cost higher than $\widetilde{F}^{\prime}$ to be financed. However, it may now also be optimal to choose $\pi=\lambda C_{2}^{H}$ for some projects that can be financed with strategic default when $\pi=\lambda C_{2}^{L}$ : If the cost of foregone renegotiation surplus resulting from $\pi=\lambda C_{2}^{H}$ is smaller than the cost of strategic default under $\pi=\lambda C_{2}^{L}$, then it is also optimal to set $\pi=\lambda C_{2}^{H}$ when this eliminates strategic default. As it turns out, the cost of strategic default exceeds the cost of foregone renegotiation whenever $\theta>\lambda$ (shown in the appendix).

Lemma 3. Suppose that $\widetilde{F}^{\prime}>\widetilde{F}$. When the ex ante setup cost exceeds $\widetilde{F}^{\prime}$, it is efficient to set the level of credit protection to $\pi=\lambda C_{2}^{H}$ if this allows the project to be financed. This is possible when $F \in\left(\widetilde{F}^{\prime}, F^{\#}\right]$.

In addition, if $\theta>\lambda$, it is also efficient to set the level of credit protection to $\pi=\lambda C_{2}^{H}$ on the interval $\left(\widetilde{F}, \widetilde{F}^{\prime}\right]$, if this allows financing the project without strategic default. Financing without strategic default with $\pi=\lambda C_{2}^{H}$ is possible as long as $F \leq \theta C_{2}^{L}+(1-\theta) \phi \lambda C_{2}^{H}$.

Lemmas 2 and 3 show that it can be efficient to raise the level of credit protection to $\lambda C_{2}^{H}$ even though this implies that renegotiation will not take place after a liquidity default when the expected date 2 cash flow is low. However, it is only efficient to do so when certain conditions are met. One possibility is that the project cannot be financed when $\pi=\lambda C_{2}^{L}$ and that raising the level of credit protection beyond $\lambda C_{2}^{L}$ allows the project to attract financing. This case obtains when $C_{2}^{H}$ is sufficiently large relative to the face value $\mathrm{R}$, as stated in condition (13). Alternatively, if financing with the low level of credit protection involves strategic default, and strategic default can be eliminated by raising the level of protection to $\pi=\lambda C_{2}^{H}$, it is optimal to do so if the 


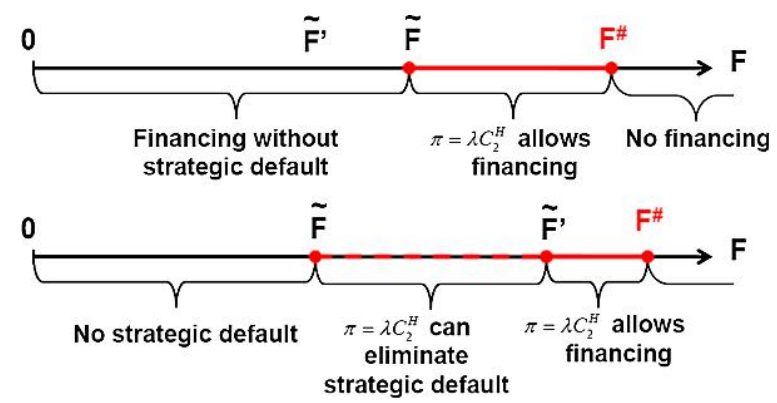

Figure 3

Raising credit protection to $\pi=\lambda C_{2}^{H}$.

The figure illustrates when it may be optimal to raise the level of credit protection to $\pi=\lambda C_{2}^{H}$. Either it must allow a project to attract financing that could not be financed with $\pi=\lambda C_{2}^{L}$ (top), or, if strategic default is sufficiently costly, it may also be optimal to set $\pi=\lambda C_{2}^{H}$ in the region where financing with $\pi=\lambda C_{2}^{L}$ would involve strategic default (bottom).

efficiency gain from eliminating strategic default outweighs the loss from not being able to renegotiate when the renegotiation surplus is low. These cases are illustrated in Figure 3.

We now summarize these findings in one proposition, which fully characterizes the socially optimal choice of credit protection.

Proposition 4. Choosing a level of credit protection $\pi=\lambda C_{2}^{H}$ is socially optimal only if

1. Projects cannot attract financing otherwise. This is the case on the interval $\left(\widetilde{F}, F^{\#}\right]$ when $\widetilde{F} \geq \widetilde{F}^{\prime}$ and on the interval $\left(\widetilde{F}^{\prime}, F^{\#}\right]$ when $\widetilde{F}^{\prime}>\widetilde{F}$.

2. Projects can only be financed with strategic default in equilibrium un$\operatorname{der} \pi=\lambda C_{2}^{L}$ and strategic default is sufficiently costly $(\theta>\lambda)$. This case arises when $\widetilde{F}^{\prime}>\widetilde{F}$ on the interval $\left(\widetilde{F}, \min \left(\widetilde{F}^{\prime}, \theta C_{2}^{L}+\right.\right.$ $\left.\left.(1-\theta) \phi \lambda C_{2}^{H}\right)\right]$.

In all other cases, the low level of credit protection, $\pi=\lambda C_{2}^{L}$, is socially optimal.

\subsection{Privately optimal credit insurance}

We now turn to the lender's privately optimal choice of credit protection. We will show that lenders will generally choose to over-insure relative to the efficient benchmark characterized in Section 3.1. Our model thus predicts that, in equilibrium, creditors may purchase credit protection in amounts that turn them into inefficient empty creditors that are excessively tough from a social perspective.

Consistent with current market practice, we assume that the lender cannot commit ex ante to a specific level of credit protection. This is a natural assumption, because according to current market practice credit derivative positions 
do not have to be disclosed, such that commitment to a certain level of credit protection is impossible. In choosing credit protection, the lender thus takes the face value $R$ as given and then chooses a level of credit protection $\pi$ that maximizes his individual payoff. The fair insurance premium $f$ in turn correctly anticipates the lender's incentives regarding renegotiation given a level of protection $\pi$. Recall that this implies that the value of CDS to the lender comes entirely from strengthening his bargaining power in situations that ultimately do not trigger payment of the CDS.

By the same argument as in Section 3.1, we know that the lender will choose a level of credit protection of at least $\lambda C_{2}^{L}$. By doing so, the lender improves his position in renegotiation without sacrificing any renegotiation surplus. However, the lender may have an incentive to raise his level of credit protection beyond $\lambda C_{2}^{L}$ to $\pi=\lambda C_{2}^{H}{ }^{12}$ In fact, the lender will always do so if the increased level of credit protection raises his expected payoff from owning the debt contract, notwithstanding any lost renegotiation surplus an increase in credit protection may cause. This means, for example, that in contrast to the efficient benchmark the lender may have the incentive to raise the level of credit protection to $\lambda C_{2}^{H}$ even in cases where the project could be financed efficiently with $\pi=\lambda C_{2}^{L}$, such that the privately optimal and socially optimal levels of credit protection differ. Proposition 5 summarizes the conditions under which privately optimal credit insurance differs from the socially optimal level of credit insurance.

Proposition 5. The creditor over-insures (inefficiently chooses $\pi=\lambda C_{2}^{H}$ ) if

1. $F \leq \widetilde{F}$ and $C_{2}^{H}$ exceeds $\bar{C}_{2}$, where

$$
\bar{C}_{2}= \begin{cases}\frac{1-\phi}{(1-q) \phi} C_{2}^{L} & \text { when } q C_{2}^{H}>C_{2}^{L} \\ \frac{1}{\phi} C_{2}^{L} & \text { otherwise. }\end{cases}
$$

2. There is an interval $\left(\widetilde{F}, \widetilde{F}^{\prime}\right]$, where financing with $\pi=\lambda C_{2}^{L}$ involves strategic default, when $C_{2}^{H}>\bar{C}_{2}$ and $\lambda>\theta$.

In all other cases, the creditor's privately optimal level of credit insurance coincides with the social optimum.

Proposition 5 shows that, in comparison to the efficient benchmark, the lender has an incentive to over-insure. Take, for example, the case when $F \leq \widetilde{F}$, such that the project could be financed efficiently with the low level of credit protection. The lender nevertheless chooses $\pi=\lambda C_{2}^{H}$ whenever this increases his payoff, i.e., whenever $C_{2}^{H}>\bar{C}_{2}$. This results in a loss of renegotiation surplus of $(1-\theta)(1-\phi) \lambda C_{2}^{L}$.

12 Again, as in Section 3.1, a level of credit protection strictly between $\lambda C_{2}^{L}$ and $\lambda C_{2}^{H}$ can never be optimal. 
More broadly, we know from Proposition 4 that it is only efficient to raise the level of credit protection to $\lambda C_{2}^{H}$ if the project could not be financed otherwise, or if the cost of foregone renegotiation surplus is more than compensated by a gain from eliminating strategic default. The creditor, however, does not fully internalize the loss in renegotiation surplus that results from choosing $\pi=\lambda C_{2}^{H}$ and over-insures in equilibrium. Our model thus predicts inefficient empty creditors as an equilibrium outcome of the lender's optimal choice credit protection choice, even when prices in the CDS market correctly anticipated the creditor's inefficient behavior in renegotiation.

Corollary 4. Assume that the project can be financed without strategic default by setting $\pi=\lambda C_{2}^{L}$. The lender will always over-insure (irrespective of the particular values of $C_{2}^{H}$ and $C_{2}^{L}$ ) when

1. The probability of the high second-period cash-flow $\phi$ tends to one.

2. $q C_{2}^{H}>C_{2}^{L}$ and $q \leq \phi$.

On the other hand, there is no over-insurance problem when either $\phi=0$ or $q=1$.

The first part of Corollary 4 shows that inefficient over-insurance by creditors is more likely when there is a high probability that in the event of a liquidity default there is ample renegotiation surplus. In this case, the incentive to capture as much surplus as possible when the renegotiation surplus turns out to be high gives creditors an incentive purchase credit insurance up to an amount that inefficiently precludes renegotiation when $C_{2}=C_{2}^{L}$. The second part of Corollary 4 shows that when $C_{2}^{H}$ is large relative to $C_{2}^{L}$, it suffices that $\phi$ exceeds $q$ for the creditor to always over-insure. This illustrates that inefficient over-insurance by creditors is more likely the higher the "upside potential" in renegotiation surplus. Finally, inspection of condition (15) shows that there is no over-insurance problem when the creditor receives the entire surplus in renegotiation $(q=1)$, or when the probability of the high date 2 cash flow is zero $(\phi=0)$.

\section{Multiple Creditors}

In this section, we explore privately optimal credit insurance in situations where the firm raises debt from multiple creditors. This extension is of interest as debt is often held by multiple creditors in practice. We will show that, under quite general conditions, the presence of multiple creditors tends to worsen the over-insurance problem in CDS markets. The reason is that individual creditors seek to strengthen their bargaining position not only with the firm but also with competing claimholders.

A firm may raise funds from multiple creditors either through a single debt issue to multiple creditors, or through multiple issues sold to a single creditor 
each. In the latter situation, the firm effectively renegotiates its debt separately with each creditor, and can treat creditors with different levels of credit protection differently. In the former situation, the firm will renegotiate with all holders of a particular issue at once, treating all creditors equally, even if they may not all be equally insured. We will look at these two cases in turn, restricting our analysis to symmetric pure-strategy equilibria. ${ }^{13}$ We will state our results in the simplest possible setting with two creditors. They generalize straightforwardly to situations with an arbitrary number of $n \geq 2$ creditors.

\subsection{Two separate debt issues}

Suppose for simplicity that the two debt issues are of equal size and seniority. Suppose also that the project can attract financing without strategic default occurring in equilibrium when $\pi_{1}+\pi_{2}=\lambda C_{2}^{L}$, the maximum level that allows efficient renegotiation after a liquidity default. We are thus restricting our analysis to cases in which an increase in credit protection beyond $\lambda C_{2}^{L}$ would invariably be inefficient. We will now show that in this situation it can be harder to sustain the socially efficient level of credit protection in an equilibrium with multiple creditors than with a single creditor. The reason is that in a setting with multiple creditors, an individual creditor is seeking to strengthen his bargaining position in renegotiation not just vis-à-vis the debtor, but also with respect to other creditors.

Recall from Proposition 5 that when a single creditor chooses his level of credit protection he would over-insure in this situation whenever $C_{2}^{H}$ exceeds the threshold $\bar{C}_{2}$. Similar to the case with one creditor, we can reduce our analysis of the two-creditor case to two potential symmetric equilibria, $\pi_{i}=\lambda C_{2}^{L} / 2$ and $\pi_{i}=\lambda C_{2}^{H} / 2 .{ }^{14}$ Let us first determine under what conditions $\pi_{i}=\lambda C_{2}^{L} / 2$ can be sustained as an equilibrium. When both creditors have protection $\pi_{i}=\lambda C_{2}^{L} / 2$, each creditor's expected payoff is given by

$$
\frac{1}{2}\left\{\theta R+(1-\theta)\left(\phi \max \left[\lambda C_{2}^{L}, q \lambda C_{2}^{H}\right]+(1-\phi) \lambda C_{2}^{L}\right)\right\} .
$$

The most profitable deviation for an individual creditor is to increase protection to $\lambda C_{2}^{H}-\pi_{j}$ (where $\pi_{j}=\lambda C_{2}^{L} / 2$ is the other creditor's level of protection). Through this deviation, the creditor can extract maximum bargaining surplus when $C_{2}=C_{2}^{H}$ and force both the firm and the other creditor down to their outside options. Increasing protection beyond this level would lead to a breakdown of renegotiation even when $C_{2}=C_{2}^{H}$ and would thus not be profitable.

13 In addition to the equilibria we analyze in this section, there may be asymmetric and symmetric mixed-strategy equilibria. A thorough analysis of these equilibria is beyond the scope of this section.

14 If $\pi_{i}<\lambda C_{2}^{L} / 2$, an individual creditor could gain by unilaterally raising his level of credit protection: Renegotiation would still always be possible, but the creditor could extract more. Similarly, when $\lambda C_{2}^{L} / 2<\pi_{i}<\lambda C_{2}^{H} / 2$, an individual creditor could gain by raising his level of credit protection: Renegotiation would still occur whenever the renegotiation surplus is high, but the creditor could extract more in renegotiation. 
Choosing a lower-level credit protection would leave money on the table for the firm or the other creditor. The payoff under this deviation is given by

$$
\frac{1}{2} \theta R+(1-\theta) \phi\left[\lambda C_{2}^{H}-\lambda \frac{C_{2}^{L}}{2}\right] .
$$

Whenever (17) exceeds (16), a symmetric pure-strategy equilibrium in which both creditors choose $\pi_{i}=\lambda C_{2}^{L} / 2$ cannot be sustained. This is the case when $C_{2}^{H}$ exceeds the cutoff $C_{2}^{*}$, which lies strictly below the cutoff in the single creditor case, $\bar{C}_{2}$.

What about the equilibrium in which both creditors choose the inefficiently high CDS position $\pi_{i}=\lambda C_{2}^{H} / 2$ ? In this case, the relevant deviation is for one creditor to reduce his level of credit protection such that renegotiation is always possible, rather than only when the renegotiation surplus is high. Assume that creditor 1 is considering this deviation. To allow renegotiation even when the renegotiation surplus is $\lambda C_{2}^{L}$, he would have to set $\pi_{1}$ such that $\pi_{1}+\lambda C_{2}^{H} / 2=\lambda C_{2}^{L}$, which means that $\pi_{1}=\lambda\left(C_{2}^{L}-C_{2}^{H} / 2\right)$. An immediate observation (under the restriction that $\pi_{i} \geq 0$ ) is that the deviation is only possible when $C_{2}^{H} \leq 2 C_{2}^{L}$. Thus, when $C_{2}^{H}>2 C_{2}^{L}, \pi_{i}=\lambda C_{2}^{H} / 2$ is always an equilibrium. Now assume that $C_{2}^{H} \leq 2 C_{2}^{L}$. The deviation payoff is given by $^{15}$

$$
\begin{aligned}
& \frac{1}{2} \theta R+(1-\theta)\left[\phi \max \left(\lambda\left(C_{2}^{L}-C_{2}^{H} / 2\right), q \lambda C_{2}^{H} / 2\right)\right. \\
& \left.\quad+(1-\phi) \lambda\left(C_{2}^{L}-C_{2}^{H} / 2\right)\right] .
\end{aligned}
$$

The deviation is profitable when this exceeds the payoff under the candidate equilibrium $\pi_{i}=\lambda C_{2}^{H} / 2$,

$$
\frac{1}{2} \theta R+(1-\theta) \phi \lambda \frac{C_{2}^{H}}{2} .
$$

Proposition 6. Suppose that the project can be financed without strategic default with two debt issues of equal size and seniority, and CDS insurance of $\pi_{i}=\lambda C_{2}^{L} / 2$. This efficient outcome can be sustained as an equilibrium whenever $C_{2}^{H}$ is smaller than $C_{2}^{*}$, where

$$
C_{2}^{*}= \begin{cases}\frac{1}{\phi(2-q)} C_{2}^{L} & \text { when } q C_{2}^{H}>C_{2}^{L} \\ \frac{1+\phi}{2} \frac{1}{\phi} C_{2}^{L} & \text { otherwise. }\end{cases}
$$

15 This expression assumes that other creditor, who has credit protection $\pi_{j}=\lambda C_{2}^{H} / 2$, receives his outside option, even after creditor 1 reduces his level of credit protection. 
The inefficient outcome $\pi_{i}=\lambda C_{2}^{H} / 2$ is an equilibrium as long as $C_{2}^{H}$ exceeds $\widetilde{C}_{2}$, where

$$
\widetilde{C}_{2}= \begin{cases}\frac{2(1-\phi)}{1-\phi q} C_{2}^{L} & \text { when } q C_{2}^{H}>2 C_{2}^{L}-C_{2}^{H} \\ \frac{2}{1+\phi} C_{2}^{L} & \text { otherwise. }\end{cases}
$$

Proposition 6 shows that multiple debt issues can worsen the over-insurance problem in CDS markets. Whenever $\widetilde{C}_{2} \leq \bar{C}_{2}$, the threshold for the existence of an inefficient over-insurance equilibrium is strictly lower in the two-creditor case than in the single-creditor case. ${ }^{16}$ Thus, multiple debt issues unambiguously worsen the over-insurance problem when $\widetilde{C}_{2} \leq \bar{C}_{2}$. This case obtains whenever the creditors' bargaining power $q$ is not too large. ${ }^{17}$ When $\widetilde{C}_{2}>\bar{C}_{2}$, on the other hand, the threshold for the inefficient (symmetric) equilibrium is higher with two creditors than with one, so that with two creditors there may be less over-insurance: On the interval $\left[\bar{C}_{2}, \widetilde{C}_{2}\right]$ the single creditor over-insures, while the two creditors, playing a symmetric mixed-strategy equilibrium (no pure-strategy equilibrium exists) in which they over-insure with probability less than one, may end up with less insurance. ${ }^{18}$

The intuition for the worsening of the over-insurance problem that can occur when there are multiple creditors in separate debt issues can be seen by considering the costs and benefits of a unilateral increase in credit protection. The individual creditor who unilaterally raises his level of credit protection extracts all the surplus from the deviation when $C_{2}=C_{2}^{H}$. The cost of the deviation, on the other hand, is shared by the two creditors: when $C_{2}=C_{2}^{L}$ renegotiation fails, and both creditors lose $\lambda C_{2}^{L} / 2$ of potential renegotiation surplus.

Proposition 6 also illustrates that with multiple creditors, each individual creditor has an incentive to increase his CDS position not just to strengthen his position vis-à-vis the firm, but also against other creditors. To see this, consider the case when $q=1$. In this case, creditors receive the entire surplus in renegotiation, even in the absence of CDS. From (15), we know that in this case a lone creditor would have no incentive to over-insure (the cutoff goes to infinity). In the two-creditor case, on the other hand, condition (21) shows

16 In the two-creditor case, this overinsurance equilbrium is unique whenever $C_{2}^{H} \geq C_{2}^{*}$. When there is an interval $\left[\widetilde{C}_{2}, C_{2}^{*}\right]$, an efficient equilibrium also exists on that interval. Whether the two creditors choose to over-insure on that interval thus depends on which equilibrium they coordinate on. Also, note that when $\widetilde{C}_{2}>C_{2}^{*}$, there is a region in which no symmetric pure-strategy equilibrium exists. In that case, a mixed-strategy equilibrium exists. For brevity, we omit characterizing this equilibrium.

17 For example, $\widetilde{C}_{2} \leq \bar{C}_{2}$ is always satisfied when $q C_{2}^{H} \leq 2 C_{2}^{L}-C_{2}^{H}$.

18 It should be noted, however, that the comparison between the one- and two-creditor outcomes in this second situation is somewhat artificial. In particular, if we allow the single creditor to hold two separate debt claims (e.g., the two claims held separately in the two-creditor scenario), and choose separate levels of protection for each of the claims, then the single creditor could always replicate any asymmetric outcome with two creditors. In that case, he would never choose more insurance protection than in an asymmetric equilibrium with two creditors. 
that over-insurance still emerges even when $q=1$ (the cutoff remains finite). The reason is that even though creditors jointly receive the entire renegotiation surplus even absent CDS, one creditor can profit at the expense of the other creditor by increasing his CDS position.

\subsection{One bond issue with multiple creditors}

Consider now a firm that has issued a single bond that is held in equal amounts by two creditors. Unlike the previous case, the firm is now required to treat the two creditors equally when it attempts to restructure this bond: It has to offer a debt exchange on the same terms, irrespective of whether the two creditors have independently purchased the same level of default protection or not. An additional complication relative to the case with two separate bond issues is that the two creditors may benefit by trading their claims with each other in anticipation of a debt restructuring. We consider in turn the situations where no trade between the two creditors is allowed, and when both bond and CDS trades are possible in a secondary market. By the same arguments as before, we can restrict our analysis to the candidate equilibria $\pi_{i}=\lambda C_{2}^{L} / 2$ and $\pi_{i}=\lambda C_{2}^{H} / 2$.

4.2.1 No trade among creditors during renegotiation. First, consider under what conditions the efficient amount of credit insurance $\pi_{i}=\lambda C_{2}^{L} / 2$ constitutes an equilibrium. The most profitable deviation for an individual creditor is to raise his level of credit protection up to $\lambda C_{2}^{H} / 2$. This is the maximum level of protection that allows renegotiation when the renegotiation surplus is high, given that both creditors have to be treated equally in renegotiation. The expected payoff from this deviation, where as before we assume that there is no strategic default, is given by

$$
\theta \frac{R}{2}+(1-\theta) \phi \frac{\lambda C_{2}^{H}}{2} .
$$

Equation (22) reflects that under equal treatment a restructuring is possible only if the firm offers $\lambda C_{2}^{H} / 2$ to each creditor, which after creditor $i$ 's deviation is only possible when the renegotiation surplus is high (i.e., with probability $\phi$ ). When the surplus is low, renegotiation fails and the creditor receives the CDS payment $\lambda C_{2}^{H} / 2$. However, in expected terms, this payment is offset by the cost of purchasing CDS protection, which under fair pricing is given by $(1-\theta)(1-\phi) \lambda C_{2}^{H} / 2$. The deviation is profitable if (22) exceeds the creditor's payoff when protection for both creditors is given by $\pi_{i}=\lambda C_{2}^{L} / 2$,

$$
\theta \frac{R}{2}+(1-\theta) \frac{1}{2}\left[\phi \max \left[\lambda C_{2}^{L}, q \lambda C_{2}^{H}\right]+(1-\phi) \lambda C_{2}^{L}\right]
$$

Comparing (22) to (23) shows that the deviation is profitable whenever $C_{2}^{H}$ exceeds $\bar{C}_{2}$ (i.e., under the same condition under which a single creditor raises his level of credit protection beyond the efficient amount). 
Now consider under what conditions $\pi_{i}=\lambda C_{2}^{H} / 2$ constitutes an equilibrium. It turns out that with two creditors in the same bond issue, $\pi_{i}=\lambda C_{2}^{H} / 2$ is always an equilibrium. To see this, consider potential deviations from this candidate equilibrium. Clearly, an individual creditor would never have an incentive to raise his level of credit protection from $\pi_{i}=\lambda C_{2}^{H} / 2$ (the only effect would be to completely rule out renegotiation). But what about lowering the level of credit protection? Under some conditions, this was a profitable deviation in the case with multiple bond issues, because the creditor's reduction in credit protection allowed for renegotiation even when the renegotiation surplus is only $\lambda C_{2}^{L}$. When both creditors are part of the same bond issue, however, this is no longer possible, since it is the creditor with the maximum amount of credit insurance who determines whether renegotiation can take place (as all creditors have to be treated equally in renegotiation). Hence, a deviation in which one creditor lowers his level of credit protection from the conjectured equilibrium $\pi_{i}=\lambda C_{2}^{H} / 2$ is not (strictly) profitable, such that $\pi_{i}=\lambda C_{2}^{H} / 2$ always constitutes an equilibrium.

We thus see that when no trade is possible among creditors, the condition under which the low level of credit protection is an equilibrium is equivalent to the condition that must be satisfied under a single creditor. However, while with a single creditor the efficient equilibrium is the only outcome when this condition is met, with multiple creditors there is a second equilibrium in which all creditors over-insure relative to the social optimum.

\subsubsection{Creditors can trade their CDS and bond positions during renego-}

tiation. Consider now the situation where the two creditors can trade their CDS and bond positions before the firm undertakes debt renegotiations. As we will show, secondary market trade between the two creditors induces the deviating creditor to be more aggressive in seeking high levels of default protection.

We start again from the candidate symmetric equilibrium in which both creditors have purchased $\pi_{i}=\lambda C_{2}^{L} / 2$ in credit protection, and ask what an individual creditor's incentives are to deviate by seeking more credit protection. The most profitable deviation for creditor $i$ is to raise his level of credit protection to $\lambda C_{2}^{H}-\lambda C_{2}^{L} / 2$. Note that absent trade among the creditors, at this level of protection renegotiation would fail even if the renegotiation surplus is high: Under equal treatment of both creditors, the firm would have to offer $2\left(\lambda C_{2}^{H}-\lambda C_{2}^{L} / 2\right)$ to guarantee that renegotiation succeeds, but this would exceed the available renegotiation surplus of $\lambda C_{2}^{H}$.

However, when trade is allowed between the two creditors, the deviating creditor can purchase the other creditor's bond and CDS position to ensure that renegotiation will be successful when the renegotiation surplus is high. To be able to purchase the other creditor's bond and CDS positions, the deviating creditor would have to pay the other creditor at least what he would receive 
if renegotiation were to fail (i.e., his CDS default payment of $\lambda C_{2}^{L} / 2$ ). After purchasing the other creditor's bond and CDS positions, the deviating creditor negotiates as a single creditor with the firm and is therefore willing to accept a restructuring offer for the whole bond issue of $\lambda C_{2}^{H}$. That is, if the firm makes an offer of $\lambda C_{2}^{H} / 2$ for each half of the bond issue, the deviating creditor who now owns the entire issue will vote to accept this offer on all the bonds he owns. The deviating creditor can thus generate a payoff of

$$
\theta \frac{R}{2}+(1-\theta) \phi\left[\lambda C_{2}^{H}-\frac{\lambda C_{2}^{L}}{2}\right]
$$

Comparing this payoff to

$$
\theta \frac{R}{2}+(1-\theta) \frac{1}{2}\left[\phi \max \left[\lambda C_{2}^{L}, q \lambda C_{2}^{H}\right]+(1-\phi) \lambda C_{2}^{L}\right]
$$

we find that the creditor is better off deviating to $\pi_{i}=\lambda C_{2}^{H}-\lambda C_{2}^{L} / 2$ whenever $C_{2}^{H}$ exceeds $C_{2}^{*}$, which is the same condition under which two creditors in two separate bond issues have an incentive to increase their credit protection beyond the efficient level.

Now consider $\pi_{i}=\lambda C_{2}^{H} / 2$ : Here, the analysis is equivalent to the case in which the two creditors cannot trade prior to renegotiation, which means that $\pi_{i}=\lambda C_{2}^{H} / 2$ always constitutes an equilibrium.

We thus conclude that the incentives to seek excessive default protection when the firm has issued a single bond held by multiple creditors lie between the incentives for over-insurance under financing with a single creditor and the incentives for over-insurance when the firm has written multiple debt contracts with multiple creditors. Given that trading among creditors has become relatively commonplace, even during times of distress, this second case may be the one that is empirically more relevant. Moreover, we have seen that the case with multiple bond issues opens up the possibility of coordination failure among creditors, since $\pi_{i}=\lambda C_{2}^{H} / 2$ always constitutes an equilibrium. We summarize these findings in Proposition 7.

Proposition 7. Assume that the firm has issued a single bond held in equal amounts by two creditors and that financing is possible without strategic default when each creditor holds $\pi_{i}=\lambda C_{2}^{L} / 2$ in credit protection.

- An inefficient equilibrium with $\pi_{i}=\lambda C_{2}^{H} / 2$ always exists. When the efficient equilibrium does not exist, $\pi_{i}=\lambda C_{2}^{H} / 2$ is the unique equilibrium.

- If creditors cannot trade their bond and CDS positions, the efficient outcome $\pi_{i}=\lambda C_{2}^{L} / 2$ is an equilibrium when $C_{2}^{H} \leq \bar{C}_{2}$ (i.e., under the same conditions as with a single creditor). 
- If creditors can trade their bond and CDS positions, the efficient outcome $\pi_{i}=\lambda C_{2}^{L} / 2$ is an equilibrium when $C_{2}^{H} \leq C_{2}^{*}<\bar{C}_{2}$ (i.e., under the same conditions as with two creditors in two separate bond issues).

\section{Discussion and Policy Implications}

In this section, we discuss the implications of our analysis for policy and the optimal legal treatment of CDS. Recall that we have highlighted two effects of CDS. On one hand, CDS serve a positive role by acting as a commitment device for borrowers to pay out cash. On the other hand, CDS can lead to socially inefficient rent extraction by protected lenders. Both of these effects arise from the same economic force: the strengthened bargaining power protected creditors have in renegotiation.

Our analysis differs from most of the existing literature on the empty creditor problem in two major ways. First, most existing papers focus only on the potential negative ex-post consequences of empty creditors. The premise of these papers, in the line of Hu and Black (2008a,b), is that the bundling of economic ownership and control rights is efficient, and hence that the introduction of CDS results in distortions, giving rise to inefficiencies. Accordingly, most studies in this strand of literature argue that it would generally be efficiency enhancing to mitigate or undo the separation of cash flow and control rights effected through CDS, thereby eliminating the empty creditor problem. Our analysis, on the other hand, indicates that any intervention should be mindful of the commitment benefits of CDS.

Second, most proposals that deal with the empty creditor problem focus on interventions in the bankruptcy process, i.e., once a firm is in Chapter $11 .{ }^{19}$ For example, Coco (2008) argues that creditors with stakes that could block a restructuring proposal in Chapter 11 should be required to disclose their hedges. The rationale is that this would allow bankruptcy courts to uncover potential conflicts of interest between those creditors in a given class that are protected by CDS and those that are not. These conflicts of interests could then be addressed, for example, by denying voting rights to protected creditors. Accordingly, $\mathrm{Hu}$ and Black (2008a, p. 21) argue that in addition to disclosure, "the degree of voting rights may need to be based on net economic ownership instead of gross ownership of a debt class." According to Fleming (2009), once in Chapter 11, this could be effected through Section 1126(e) of the Bankruptcy Code, which allows disenfranchising creditors whose votes in Chapter 11 are "not in good faith."

However, given the form of most CDS contracts, it is not obvious that a conflict between protected and unprotected creditors always remains in bankruptcy, as the CDS payment is a bygone once the firm is in Chapter 11 and CDS

19 One notable exception is Hemel (2010), which we discuss below. 
contracts have been settled. ${ }^{20}$ Hence, as Baird and Rasmussen (2010, p. 42) point out, "[c]redit default swaps create a moral hazard problem only before Chapter 11 begins and then in its immediate aftermath." Thus, the focus on disclosure and on denying voting rights to protected creditors in bankruptcy may be misplaced. In contrast, our analysis suggests that the critical legal intervention is likely to be prior to a bankruptcy filing, with a focus on eliminating inefficient obstacles to debt restructuring outside of Chapter 11, while preserving the commitment benefits of CDS. In what follows, we briefly discuss to what extent a number of specific proposals satisfy this criterion.

\subsection{Removal of voting rights}

Given that in our analysis CDS lead to ex ante commitment benefits by strengthening creditors' ex post bargaining power, it is inefficient to remove the creditor's voting rights unless CDS give rise to significant ex post debt restructuring inefficiencies. Thus, as a general principle it would be efficient to uphold a protected creditor's voting rights in a debt restructuring proposal or exchange offer, unless it can be shown that the CDS protection is likely to lead to a breakdown in a value-enhancing debt restructuring deal. This implies that it would be inefficient if the mere presence of CDS protection led to an automatic denial of voting rights in debt restructuring (e.g., by requiring that voting rights must reflect net economic ownership). In particular, as long as the effect of CDS protection is only to change the terms of the restructuring deal in favor of the creditor, then there is no reason to intervene either in the debt contract or the CDS, since in this case, the denial of voting rights to hedged creditors would erode the ex ante benefits of CDS.

\subsection{Making debt restructuring a credit event}

Our analysis has assumed that out-of-court debt restructuring does not constitute a credit event for the CDS contract. This corresponds to current market practice, as the standard North American CDS as defined by ISDA does not count restructuring as a credit event (JPMorgan 2009). Moreover, even when a restructuring event is included in a CDS contract, it is often not clear whether a voluntary debt restructuring will constitute a credit event for the CDS. ${ }^{21}$

20 Clearly, once all CDS are settled, they should not matter in Chapter 11. It is possible, however, that important decisions - in particular whether to grant DIP financing - have to be made before all CDS contracts are settled. To the extent that the default payment by the protection seller is unaffected, these decisions should not depend on the presence of unsettled CDS. If, however, the default payment is inversely related to the recovery (or continuation) value of the firm in Chapter 11, as is often the case in practice, creditors that are net short through their CDS position may not have an incentive to maximize continuation value. From this perspective, it is desirable to settle CDS positions as quickly as possible after a Chapter 11 filing.

21 Restructuring was originally included as a credit event in the 1999 ISDA credit derivatives definitions. However, problems with restructuring clauses emerged when Conseco Finance restructured debt to terms that were advantageous to creditors, yet still this restructuring counted as a credit event. As a consequence, contracts that did not include restructuring as a credit event gained in popularity. Moreover, for investors that wanted restructuring included in their CDS contracts, ISDA introduced modified versions of the restructuring clause. The modified restructuring clause of 2001 (Mod-R) and the modified-modified restructuring clause introduced in 2003 (ModMod-R) limit the set of securities a lender can deliver in the case of a restructuring credit event. For more details on the different contractual clauses, see JPMorgan (2006). 
While it is well known that the different treatment of restructuring events affects the pricing of CDS contracts (Packer and Zhu 2005; Berndt, Jarrow, and Kang 2006), our model implies that in addition this contractual difference also has important repercussions on creditor behavior and credit market outcomes. In particular, making (voluntary) restructuring a credit event constitutes one simple way of eliminating the empty creditor problem altogether. In this case, the default payment $\pi$ would be made whether or not debt restructuring is successful, such that the CDS has no effect on the creditor's incentives in debt restructuring.

Along these lines, Hemel (2010) argues for the inclusion of a broad restructuring clause that includes voluntary debt exchanges in all CDS contracts. However, recall that in our model the economic value added by CDS stems from their role as a commitment device. In particular, a creditor with CDS protection becomes a tougher counterparty in renegotiations only if the CDS contract does not trigger a default payment when an out-of-court restructuring agreement is reached. It follows that if restructuring is included as a credit event, CDS lose their economic role in our model. Hence, while classifying restructuring as a credit event eliminates restructuring inefficiencies resulting from the empty creditor problem, it also eliminates any economic gains from CDS as a commitment device. ${ }^{22}$

\subsection{Ex post interventions by the protection seller}

In our formal analysis, the protection seller remains passive when the debtor and creditor renegotiate. This effectively rules out Coasian bargaining that may alleviate the inefficiencies caused by empty creditors. One implication of this is that active involvement by the protection seller may reduce the inefficiencies created by CDS. Let us give two brief examples.

One avenue for the protection seller to avoid default, and the CDS payment of $\pi=\lambda C_{2}^{H}$ to the creditor, is to directly help the debtor repay the debt obligation $R$ at date 1 . If the protection seller fears an inefficient breakdown in renegotiation, all he needs to do is cover the difference $R-C_{1}^{L}$ of the debt obligation. Hence, as long as $R-C_{1}^{L} \leq \lambda C_{2}^{H}$, this is an attractive alternative for the protection seller. In fact, the Texan brokerage firm Amherst Holdings pursued exactly this strategy to avoid default payments on CDS contracts it had sold to investment banks such as JPMorgan Chase, Royal Bank of Scotland, and Bank of America (Zuckerman, Ng, and Rappaport 2009). Our analysis suggests that such interventions are efficiency improving ex post.

22 A related way around the empty creditor problem would be to structure CDS like a put option. Rather than requiring a contractually specified default event, one could imagine a contract according to which the protection buyer can sell (put) the bond to the protection seller for a prespecified price at any time. In this case again, the presence of CDS would have no effect on debt restructuring. However, as with debt restructuring as a credit event, the put option CDS would also eliminate the beneficial commitment role of CDS. 
An alternative way for the protection seller to avoid the inefficiency that arises from the failure to renegotiate is to purchase the debt claim from the protection buyer in cases where renegotiation between the debtor and creditor breaks down. In order to examine this in the context of our model, recall that debt renegotiation breaks down when the CDS specifies a high default payment, $\pi=\lambda C_{2}^{H}$, and when $C_{2}=C_{2}^{L}$, such that the available renegotiation surplus is given by $\lambda C_{2}^{L}$. If the protection seller purchases the debt claim from the initial lender, there will be efficient debt renegotiation and therefore no default by the firm. This means that the initial lender would be denied the default payment $\pi=\lambda C_{2}^{H}$ under the CDS. Thus, to purchase the debt claim, the protection seller must pay the initial lender at least this amount. Then, by renegotiating with the firm, the protection seller can receive $q^{I} \lambda C_{2}^{L}$, where $q^{I}$ denotes the protection seller's bargaining power in renegotiation. The net payment the protection seller needs to make if he purchases the debt claim is thus given by $\lambda C_{2}^{H}-q^{I} \lambda C_{2}^{L}$. If the protection seller does not purchase the debt claim, renegotiation will fail and the protection seller has to make a payment on the outstanding CDS of $\pi=\lambda C_{2}^{H}$. This suggests a potential role for protection sellers to purchase outstanding debt in cases when renegotiation between the debtor and the original creditor fails.

However, while the Amherst case provides an example of protection sellers making direct payments to avoid default on issues, we are not aware of cases in which sellers of protection have bought up the outstanding debt of an issuer in order to avoid a breakdown of renegotiation. It is an open question whether this is the case because protection sellers are not taking a sufficiently active role to avoid inefficient defaults due to empty creditors, or whether there are other difficulties, such as locating the holders of the debt, that prevent this intervention in practice.

\subsection{Disclosure may allow contracting on CDS positions}

According to current market practice, there are few disclosure requirements for bond positions and almost no disclosure requirements for CDS positions. Prior to a Chapter 11 filing, neither bond nor CDS positions have to be disclosed. Once in Chapter 11, rule 2019(a) requires ad hoc committees to disclose their security positions, but usually not their derivatives positions.

However, the current debate about moving CDS to organized exchanges (e.g., Duffie and Zhu 2009; Stulz 2010) has gone hand in hand with a debate on transparency and potential disclosure requirements for CDS positions. While much of the debate on disclosure has focused on the ability to identify risk concentrations, our model highlights another potential benefit of CDS position disclosure: Requiring disclosure may allow market participants to contract on CDS positions. Specifically, in our model this may allow the lender to commit not to over-insure once he has acquired the bond (e.g., by requiring both the borrower and the lender to agree to the CDS position). This would limit unilateral, rent-seeking default protection by the creditor at the expense 
of the firm, thus overcoming the empty creditor problem. ${ }^{23}$ Finally, even if such commitment to CDS positions is not possible, public disclosure of CDS positions would allow the public to gauge creditors' incentives when the firm is in distress.

\section{Conclusion}

In this article, we propose a limited commitment model of credit default swaps. While many commentators have raised concerns about the ex post inefficiencies created by the empty creditor problem that arises when a debt holder has obtained insurance against default but otherwise retains control rights, our analysis shows that CDS add value by acting as a commitment device for borrowers to pay out cash. Hence, CDS have important ex ante commitment benefits. Specifically, they increases investment and, by eliminating strategic default, can make existing projects more efficient. However, we also show that when creditors are free to choose their level of credit protection, they will generally over-insure, resulting in an empty creditor problem that is inefficient both ex post and ex ante. This over-insurance occurs even when CDS markets perfectly anticipate the inefficient behavior of empty creditors, and leads to excessive incidence of bankruptcy and too little renegotiation with creditors relative to first-best.

Our analysis leads to a more nuanced view on policy than most of the existing law and economics literature. In particular, any policy response to inefficiencies arising from the empty creditor problem should be mindful of the beneficial commitment role of CDS. Eliminating empty creditors altogether (e.g., by stripping protected creditors of their voting rights or by making restructuring a credit event) would be inefficient in our framework. An approach that may avoid such inefficiencies would be to cap enforceable CDS payments or to make CDS positions subject to approval by both the debtor and the creditor. Moreover, disclosure of CDS positions may help alleviate the problem by allowing debtors and creditors to contract on CDS positions taken by creditors.

\section{Appendix}

\section{A.1. Proofs}

Proof of Lemma 2: Suppose that $\widetilde{F} \geq \widetilde{F}^{\prime}$. Consider a project whose setup cost exceeds $\widetilde{F}$. This project cannot be financed when setting $\pi=\lambda C_{2}^{L}$. Increasing the amount of credit protection to $\pi=\lambda C_{2}^{H}$ is efficient if it allows the project to receive financing. This is the case if increasing the amount of credit protection to $\lambda C_{2}^{H}$ increases the amount the firm can pledge to the creditor relative to the case where $\pi=\lambda C_{2}^{L}$. When $\pi=\lambda C_{2}^{L}$, the firm can pledge a maximum of

$$
\widetilde{F}=\theta C_{2}^{L}+(1-\theta)\left(\phi \max \left[\lambda C_{2}^{L}, q \lambda C_{2}^{H}\right]+(1-\phi) \lambda C_{2}^{L}\right)
$$

\footnotetext{
23 Note that in our analysis this type of disaggregated disclosure to facilitate contracting or gauge renegotiation
} incentives would only need to apply to investors who simultaneously hold the underlying bond or loan. 
to the creditor, where the face value of debt is set to the highest value compatible with no strategic default in the high cash-flow state, i.e., $R=C_{2}^{L}$. The maximum ex ante face value that can be financed when $\pi=\lambda C_{2}^{H}$ is given by

$$
F^{\#}=\theta \max \left[C_{2}^{L}, \phi C_{2}^{H}\right]+(1-\theta) \lambda C_{2}^{L},
$$

where the first part of the expression depends on whether $R=C_{2}^{L}$ or $R=C_{2}^{H}$. However, $\widetilde{F} \geq \widetilde{F}^{\prime}$ implies that $C_{2}^{L}>\phi C_{2}^{H}$ such that the relevant case is

$$
F^{\#}=\theta C_{2}^{L}+(1-\theta) \lambda C_{2}^{L}
$$

There is a positive interval of setup costs where setting $\pi=\lambda C_{2}^{H}$ allows financing a project that could otherwise not attract financing whenever $F^{\#}>\widetilde{F}$. From (A1) and (A3), we know that this is the case whenever

$$
\phi \lambda C_{2}^{H}>\phi \max \left[\lambda C_{2}^{L}, q \lambda C_{2}^{H}\right]+(1-\phi) \lambda C_{2}^{L} .
$$

Simplifying (A4) yields the cutoff $\bar{C}_{2}$.

Proof of Lemma 3: Suppose that $\widetilde{F}^{\prime}>\widetilde{F}$. Clearly, when setting $\pi=\lambda C_{2}^{H}$ allows financing a project that could otherwise not be financed $\left(F>\widetilde{F}^{\prime}\right)$, it is optimal to do so. This is the case when the maximum pledgeable cash flow with $\pi=\lambda C_{2}^{H}$ exceeds $\widetilde{F}^{\prime}$, i.e., when

$$
\begin{aligned}
\theta \max \left[\phi C_{2}^{H}, C_{2}^{L}\right]+(1-\theta) \phi \lambda C_{2}^{H}> & \theta\left[\phi C_{2}^{H}+(1-\phi) \lambda C_{2}^{L}\right] \\
& +(1-\theta)\left(\phi \lambda \max \left[C_{2}^{L}, q C_{2}^{H}\right]+(1-\phi) \lambda C_{2}^{L}\right) .
\end{aligned}
$$

In addition, if the cost of foregone renegotiation surplus, $(1-\theta)(1-\phi) \lambda C_{2}^{L}$, is smaller than the cost of strategic default, $\theta(1-\phi)(1-\lambda) C_{2}^{L}$, it is optimal to set $\pi=\lambda C_{2}^{H}$ and $R=C_{2}^{L}$ also on the interval $\left(\widetilde{F}, \widetilde{F}^{\prime}\right]$ to eliminate strategic default, as long as this allows financing. This is possible as long as $F<\theta C_{2}^{L}+(1-\theta) \phi \lambda C_{2}^{H}$. Comparing the two expressions above, it is easy to see that the cost of foregone renegotiation surplus is smaller than the cost of strategic default when $\theta>\lambda$.

Proof of Proposition 4: Follows from Lemmas 1, 2, and 3.

Proof of Proposition 5: Suppose that $F \leq \widetilde{F}$ such that efficient financing is possible with $\pi=$ $\lambda C_{2}^{L}$. The creditor will nevertheless choose $\pi=\lambda C_{2}^{H}$ when this increases his expected payoff. This is the case when

$$
\theta R+(1-\theta) \phi \lambda C_{2}^{H}>\theta R+(1-\theta)\left[\phi \max \left[\lambda C_{2}^{L}, q \lambda C_{2}^{H}\right]+(1-\phi) \lambda C_{2}^{L}\right],
$$

which is satisfied when $C_{2}^{H}>\bar{C}_{2}$. In contrast to the socially optimal outcome in Section 3.1, the creditor will choose to raise his level of credit protection to $\lambda C_{2}^{H}$ if it increases his expected payoff, irrespective of whether the project can be financed when $\pi=\lambda C_{2}^{L}$.

Now consider $F \in\left(\widetilde{F}, \widetilde{F}^{\prime}\right]$. When this interval is non-empty, the project can only be financed with strategic default when $\pi=\lambda C_{2}^{L}$. If the project could be financed without strategic default when $\pi=\lambda C_{2}^{H}$, it is efficient to do so when the costs of strategic default outweigh the cost of lost renegotiation surplus, which is the case when $\theta>\lambda$. In that case, the firm can issue debt with an appropriate face value of $R \leq C_{2}^{L}$. Creditors would respond by setting $\pi=\lambda C_{2}^{H}$ and break even on their investment. However, when $\theta<\lambda$, it would be efficient for the firm to issue debt with face value $R>C_{2}^{L}$, where $R$ is chosen such that creditors break even by setting $\pi=\lambda C_{2}^{L}$. However, creditors will inefficiently choose $\pi=\lambda C_{2}^{H}$ when this increases 
their payoff. Proceeding analogously to the proof of Proposition 5, we find that this is the case whenever $C_{2}^{H}>\bar{C}_{2}$.

Proof of Corollary 4: The first statement is a direct consequence of taking the limit $\phi \rightarrow 1$ in Equation (15). When $q C_{2}^{H}>C_{2}^{L}$, the cutoff $\frac{1-\phi}{(1-q) \phi} C_{2}^{L}$ converges to zero as $\phi \rightarrow 1$. When $q C_{2}^{H} \leq C_{2}^{L}$, the cutoff $\frac{1}{\phi} C_{2}^{L}$ converges to one. In both cases, the condition for over-insurance is always satisfied since $C_{2}^{H}>C_{2}^{L}>0$. To see the second statement of the corollary, note that, when $q C_{2}^{H}>C_{2}^{L}$, over-insurance will always occur if $\bar{C}_{2}$ is smaller than the lowest possible realization of $C_{2}^{H}$ (which is $\frac{1}{q} C_{2}^{L}$ in this case). This is satisfied when $\frac{1-\phi}{(1-q) \phi} C_{2}^{L} \leq \frac{1}{q} C_{2}^{L}$, which simplifies to $q<\phi$. The cases $\phi=0$ and $q=1$ follow straightforwardly from (15).

\section{A.2. Alternative bargaining protocol}

In this section, we discuss how our results on the socially and privately optimal levels of credit insurance would change if we varied the bargaining protocol used to determine the split of surplus between the debtor and the creditor. The purpose is to show that while some of the specific expressions calculated in the article would change, this alternative bargaining specification leads to the same qualitative results as the "outside option principle." For brevity, we focus on the single creditor case.

Instead of the Binmore-Shaked-Sutton "outside option principle" used in the article, assume that in renegotiation the creditor receives his outside option $\pi$ plus a share $q$ of the remaining bargining surplus, if any. Under this alternative specification, the creditor's payoff in renegotiation is given by

$$
\pi+\max \left[q\left(\lambda C_{2}-\pi\right), 0\right] .
$$

In terms of the analysis in the article, this would result in two major changes. First, some of the cutoff values for the maximum setup cost that allows financing would change. Consider, for example, the maximum setup cost that allows financing without strategic default when the creditor has protection $\lambda C_{2}^{L}$, which in the article is denoted by $\widetilde{F}$. Under the alternative bargaining specification, $\tilde{F}$ becomes

$$
\widetilde{F}=\theta C_{2}^{L}+(1-\theta)\left[\lambda C_{2}^{L}+\phi q\left(C_{2}^{H}-C_{2}^{L}\right)\right] .
$$

The maximum setup value that allows financing with strategic default when the creditor has protection $\lambda C_{2}^{L}$ would change in an analogous fashion. The cut-off $F^{\#}$, on the other hand, remains unchanged, since the change in bargaining setup has no effect on payoffs when $\pi=\lambda C_{2}^{H}$. This means that Proposition 4 would still hold, with the appropriate adjustments in $\widetilde{F}$ and $\widetilde{F}^{\prime}$.

The second change relative to the analysis in the article is that the condition under which an increase of the level of credit protection from $\pi=\lambda C_{2}^{L}$ to $\pi=\lambda C_{2}^{H}$ increases the payoff to the creditor changes. Following the same steps as in the analysis in the article, we find that under the alternative bargaining specification (A7), raising the level of credit protection increases the payoff to the creditor whenever

$$
\phi \lambda C_{2}^{H}>\phi\left[\lambda C_{2}^{L}+q \lambda\left(C_{2}^{H}-C_{2}^{L}\right)\right]+(1-\phi) \lambda C_{2}^{L} .
$$

Simplifying this condition, we find that the cutoff for $C_{2}^{H}$ that satisfies this condition changes relative to the analysis in the article, and is now given by

$$
\bar{C}_{2}=\frac{1-q \phi}{(1-q) \phi} C_{2}^{L} .
$$

With this adjustment in place, however, Proposition 5 would continue to hold as before. We thus see that none of the economic results of the article change under this alternative bargaining setup. 


\section{References}

Allen, F., and E. Carletti. 2006. Credit Risk Transfer and Contagion. Journal of Monetary Economics 53: $89-111$.

Arping, S. 2004. Credit Protection and Lending Relationships. Working Paper, University of Amsterdam.

Ashcraft, A. B., and J. A. C. Santos. 2009. Has the CDS Market Lowered the Cost of Corporate Debt? Journal of Monetary Economics 56:514-23.

Baird, D. G., and R. K. Rasmussen. 2010. Anti-bankruptcy. Yale Law Review 119:648-99.

Batchelor, C. 2004. Restructuring at Risk from CDSs. Financial Times, October 18.

Berman, D. K. 2010. YRC and the Street's Appetite for Destruction. Wall Street Journal, January 5.

Berndt, A., R. A. Jarrow, and C. Kang. 2006. Restructuring Risk in Credit Default Swaps: An Empirical Analysis. Working Paper, Carnegie Mellon University.

Bolton, P., and D. S. Scharfstein. 1990. A Theory of Predation Based on Agency Problems in Financial Contracting. American Economic Review 80:93-106.

1996. Optimal Debt Structure and the Number of Creditors. Journal of Political Economy 104:1-25.

Brav, A., and R. D. Mathews. 2011. Empty Voting and the Efficiency of Corporate Governance. Journal of Financial Economics 99:289-306.

Bris, A., I. Welch, and N. Zhu. 2006. The Costs of Bankruptcy: Chapter 7 Liquidation versus Chapter 11 Reorganization. Journal of Finance 61:1253-303.

Burning Down the House. 2009. Economist, May 5.

CDSs and Bankruptcy: No Empty Threat. 2009. Economist, June 18.

Coco, K. J. 2008. Empty Manipulation: Bankruptcy Procedure Rule 2019 and Ownership Disclosure in Chapter 11 Cases. Columbia Business Law Review 611:610-56.

Duffee, G. R., and C. Zhou. 2001. Credit Derivatives in Banking: Useful Tools for Managing Risk? Journal of Monetary Economics 48:25-54.

Duffie, D., and H. Zhu. 2009. Does a Central Clearing Counterparty Reduce Counterparty Risk? Working Paper, Stanford University.

Fink, R. 2004. Default Swap Faults. CFO Magazine, October 1.

Fleming, P. D. 2009. Credit Derivatives Can Create a Financial Incentive for Creditors to Destroy a Chapter 11 Debtor: Section 1126(e) and Section 105(a) Provide a Solution. ABI Law Review 17:189-215.

Hart, O., and J. Moore. 1994. A Theory of Debt Based on the Inalienability of Human Capital. Quarterly Journal of Economics 109:841-79. $1-41$.

1998. Default and Renegotiation: A Dynamic Model of Debt. Quarterly Journal of Economics 113:

Hemel, D. 2010. Empty Creditors and Debt Exchanges. Yale Journal on Regulation 27:159-70.

Hirtle, B. 2009. Credit Derivatives and Bank Credit Supply. Journal of Financial Intermediation 18:125-50.

Hu, H. T. C., and B. Black. 2006. The New Vote Buying: Empty Voting and Hidden (Morphable) Ownership. Southern California Law Review 79:811-908.

2007. Hedge Funds, Insiders, and the Decoupling of Economic and Voting Ownership: Empty Voting and Hidden (Morphable) Ownership. Journal of Corporate Finance 13:343-67.

2008a. Debt, Equity, and Hybrid Decoupling: Governance and Systemic Risk Implications. European Financial Management 14:663-709. 
2008b. Equity and Debt Decoupling and Empty Voting II: Importance and Extensions. University of Pennsylvania Law Review 156:625-739.

JPMorgan. 2006. Credit Derivatives Handbook. JP Morgan Corporate Quantitative Research, December. 2009. Credit Market Outlook and Strategy. North America Credit Research, 20 February.

Kahan, M., and E. B. Rock. 2007. Hedge Funds in Corporate Governance and Corporate Control. University of Pennsylvania Law Review 155:1021-93.

Kalay, A., and S. Pant. 2009. Time varying voting rights and the private benefits of control. SSRN working paper.

King, N., and J. McCracken. 2009. Chrysler Chapter 11 Is Imminent. Wall Street Journal, April 30.

Liar's Poker. 2003. Economist, May 15.

Lubben, S. J. 2007. Credit Derivatives and the Future of Chapter 11. Working Paper, Seton Hall University School of Law.

Morrison, A. C. 2005. Credit Derivatives, Disintermediation, and Investment Decisions. Journal of Business 78:621-47.

Packer, F., and H. Zhu. 2005. Contractual Terms and CDS Pricing. BIS Quarterly Review, pp. 89-100.

Parlour, C. A., and G. Plantin. 2008. Loan Sales and Relationship Banking. Journal of Finance 63:1291-314.

Parlour, C. A., and A. Winton. 2008. Laying off Credit Risk: Loan Sales versus Credit Default Swaps. Working Paper, UC Berkeley.

Partnoy, F., and D. A. Skeel. 2007. The Promise and Perils of Credit Derivatives. University of Cincinnati Law Review 75:1019-36.

Rajan, R. G. 1992. Insiders and Outsiders: The Choice between Informed and Arm's-length Debt. Journal of Finance 47:1367-400.

Rosenwald, M. S. 2009. Plaqued by Debt, Six Flags Faces Its Own Wild Ride. Washington Post, p. A10, April 13.

Saretto, A., and H. Tookes. 2010. Corporate Leverage, Debt Maturity, and Credit Default Swaps: The Role of Credit Supply. Working Paper, Yale University.

Sender, H. 2005. Hedge-fund Lending to Distressed Firms Makes for Gray Rules and Rough Play. Wall Street Journal, July 18.

\footnotetext{
_.2009a. CDS Derivatives Are Blamed for Role in Bankruptcy Filings. Financial Times, April 17.

- 2009b. CDS Investors Hold the Cards. Financial Times, July 22.

_.2009c. Credit Insurance Hampers GM Restructuring. Financial Times, May 11.
}

Shareholders in Mirant Gain Voice in Renegotiation. 2003. New York Times, September 20.

Stulz, R. 2010. Credit Default Swaps and the Credit Crisis. Journal of Economic Perspectives 24(1):75-92.

Sutton, J. 1986. Non-cooperative Bargaining Theory: An Introduction. Review of Economic Studies 53: 709-24.

Thompson, J. R. 2007. Credit Risk Transfer: To Sell or to Insure. Working Paper, University of Waterloo.

Weistroffer, C. 2009. Credit Default Swaps: Heading Toward a More Stable System. Deutsche Bank Research Current Issues.

Yavorsky, A. 2009. Analyzing the Potential Impact of Credit Default Swaps in Workout Situations. Special Comment, Moody's Investor Services. 
Zachariadis, K., and I. Olaru. 2010. Trading and Voting in Distressed Firms. Working Paper, London School of Economics.

Zuckerman, G., S. Ng, and L. Rappaport. 2009. A Daring Trade Has Wall Street Seething: Texas Brokerage Firm Outwits the Big Banks in a Mortgage-related Deal, and Now It's War. Wall Street Journal, June 12. 